\title{
Cavalry Horsemanship
}

and

Horse Training.

Lit. Col. Blacque Belair 


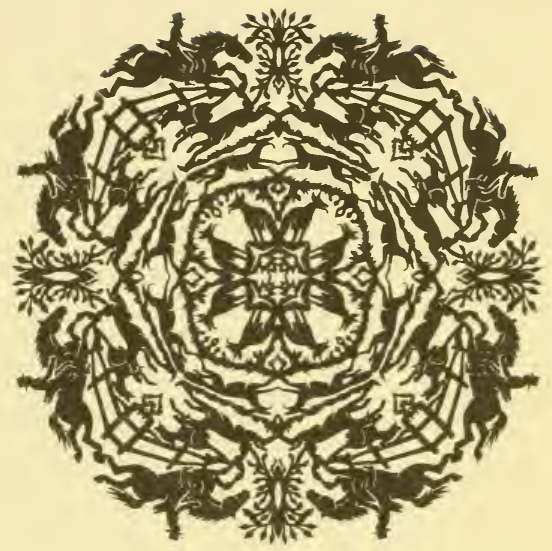

JOHN A.SEAVERNS 


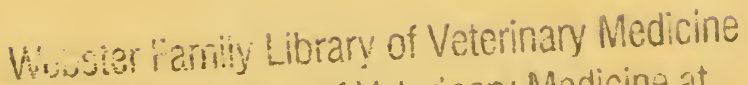
Currmings School of Veterinary Medicine at Turis University 200 Westooro hoad North Grafton, MA 01536 
$\frac{6}{6}$

From: fins 


\section{CAVALRY HORSEMANSHIP}

AND

\section{HORSE - TRAINING}

(RISPONSES AU QUESTIONNAIRE I)'ÉQUITATION

DE L'ÉCOLE DE CAVALFRIT)

BY

\section{Lieut. $=$ Col. BLACQUE BELAIR}

Chlef Instructor at the Cavalry School, Saumur, France

TRANSLATED FROM THE FRENCH

BY

JOHN SWIRE

Author of Anglo.French Horsemanship, and Translator of F. Baucher's Principles of Horsemanship

ENGLISII COPYRIGHT RESERVED

I. ONDON

VINTON \& COMPANY, LTD.

8, Bream's Buildings, Chancery Lane, E.C. + 
BI THE SAME AUTHOR Demy 8vo. With 12 Full-page Illustrations.

\title{
ANGLO FRENCH HORSEMANSHJP
}

\author{
BY \\ JOHN SWIRE
}

F'eap. 8vo. ('loth, 5s, net.

\section{THE PRINCIPLES}

OF

\section{HORSEMANSHIP}

BY

F. BAUCHER

T'ranslated from the French by JOHN SWIRE

VINTON \& COMPANY, LTD.

8, Bream's Bldgs., Chancery Lane, E.6. 


\section{PREFACE}

I cAxNot too strongly recommend this excellent and comprehensive work of Colonel Blacque Belair's to all students of the Art of Equitation. It has been of the utmost assistance to those who have, during the past year, been entrusted with the task of teaching, though perforce hurriedly, the elements of this complex subject.

It has, I think, been conclusively proved, more than ever during the present war, that any time spent on Equitation, whether applied to trooper or troop horse, has not been wasted.

As the life-taking mechanical appliances improve in efficiency, so must the Cavalry, by means of their training, increase their power to manœuvre rapidly, and adopt with the maximum speed and smoothness, formations which are at the same time elastic and comprehensive.

The Germans, in March, 1918, found to their cost that without Cavalry their army was not able to reap the fruits of victory. The Allies, by means of theirs, have been able to strike decisive blows in all the many theatres of war.

Equitation is the basis on which the whole training 
of Cavalry rests; the sound principles, the logical sequence, and, above all, the clear explanation, all go to make this book the greatest help towards the attainment of this end.

\section{MALCOLM BORIVICK,}

\section{Major, Royal Scots Greys,}

Commandant, Cavalry Corps Equitation School.

October, 1918.

B.E.F., France. 


\section{'TRANSLATOR'S PREFACE}

Is publishing this translation of a book which, whilst simple in its teaching, is naturally at times technical in its language, I gratefully acknowledge the assistance received from the instructors at the Cavalry Corps Equitation School, B.E.F., France, amongst whom I have pleasure in mentioning Major M. Borwick, D.S.O., Commandant, Royal Scots Greys; Captain P. E. Bowden Smith, 19th Hussars; Captain J. J. Pearce, Queen's Own Oxfordshire Hussars; Captain J. K. Swire, Essex Yeomanry.

\section{J. SWIRE.}

HillingdoN House, Harlow, Essex. 



\section{CONTENTS}

Preface . . . . . . . . . . . . ${ }^{\text {PAGE }}$

Generalties . . . . . . . . . . 1

1st Part.-The Education of the Rider . . . 1

2nd Part.-The Education of the Horse . . . 3

3rd Part.-Application of the Principles of Horsemanship and of Training to the Management of the Horse . . . 3

\section{PART I}

\section{THE EDUCATION OF THE RIDER}

\section{CHAPTER I}

\section{ELEMENTARY HORSEMANSHIP}

Qualities of the Instructor

Endurance-Commonsense-Love of method-Faith.

What should be aimed at

Giving confidence to the horseman-Causes and remedies for contractions.

The Means of keeping in the Saddle

The seat-Its influence on the action of the hands- The stirrups-Usefulness in out-door work. 
Special Gymnastic Exercises

Control of the reflexes-The independent action of the hands with regard to the movement of the body and legs-The independence of the hands and legs of each other-Exercises which help the acquisition of this independence.

\section{The Rider's Position}

How to place the rider on the horse-How to make his seat firm-Relative value of the position of the different parts of the body-Importance of the proper use of the eyes-Being one with the horse.

Suppling Exercises

\section{CHAPTER_II \\ SECONDARY EQUITATION}

Horse Control

The Fundamental Principles

To understand the means of action (study of the aids)-To be master of the means of action (the discipline of the aids)-To know how to utilize these means of action (employment of the aids).

Study of the Aids .

Value of Moral Qualities and Physical Aptitudes 14

The Natural Aids . . . . . . . . 14

The action of the legs-The action of the reins.

Harmony of the Aids: Definition

1st, Harmony between the legs acting together and both reins acting together-2nd, Harmony of the two reins$3 r d$, Harmony of the legs-4th, Harmony of the legs with each of the effects of the reins.

Using the Weight of the Body as an Aid

Lateral and Diagonal Aids-Lateral and Diagonal Effects

Employment and relative value. 
Discipline of the Aids

The seat-Right use of the legs and hands.

\section{CHAPTER III \\ SUPERIOR EQUITATION}

\section{Education of the Officer}

Aim of this instruction-The impulsive horse, straight going and light in hand.

\section{PART II \\ EDUCATION OF THE HORSE}

\section{CHAPTER I}

\section{The Saddle Horse}

Qualities and aptitudes-The perfect shape-Quality.

\section{CHAPTER II}

\section{Generalities}

Influence and responsibility of the commanding officer and of the squadron leader-Qualities of the instructor and the trainers' care on arrival at the regiment-The object of the education of the young horse.

\section{Divisions .}

Breaking in and training-Their characteristics-Circumstances which influence the duration of the education of the young horse-Important rules. 


\section{CHAPTER III}

\section{BREAKING}

The Object of Breaking Phases

The Importance of Work

Dismounted Work

Work on the lunging rein-Getting horse used to the saddle-The mounting lesson-Training to the sword.

Mounted Work

Early education in the aids-The walk-The halt-Turning-The rein back-First lessons in the canter.

Conditioning Work

Organization of the Lessons

Value of the different paces-The trot-The canter-

Oppositions of the young horse.

Preparation of the Young Horse for his eventual employment in case of Mobilization . . . . 74 The Bridle

Individual Work .

Early Jumping Lessons

Training in hand-Jumping on the lunging rein-Jumping at liberty-Jumping mounted.

Stable Management

Grooming-Weekly examination-Change of coat and green food-Choice of ground.

\section{CHAPTER IV}

TRAINING

Generalities

The System recommended: Method and Progression 
The Principal Factors in Training .

The instructor-The rider-The work-The duration of training.

\section{The Psychology of Training}

Influence of character and conformation-Nature of the training-The basis of equestrian language-Association of sensations.

The Principles of Movement

Impulsion-Balance-Locomotion-The rôle and position

. of the head in movement-The rôle and position of the neck.

Special Exercises for the Young Horse .

The Resistances:-

(A) How to obtain the engagement and mobility of the hindquarters.

(B) How to supple the spine.

(C) How to develop the free play of the shoulders.

(D) How to supple the lower jaw.

Movement to the side and shoulder.

Easing the Hand and Extension of the Neck . 112

Balancing-Working on a long or short base.

Observations on the Paces . . . . . . 115

The Start of the Canter or Gallop . . . . . 119

Jumping when mounted . . . . . . 124

PART III

\section{APPLICATION OF THE PRINCIPLES OF HORSEMANSHIP AND TRAIN- ING T'O THE CONTROL OF THE HORSE.}

CHAPTER I

THE EMPLOYMENT OF THE TRAINED HORSE BY THE TRAINED MAN

The Straight-moving Horse To change the Pace and Speed . 
PAGE

To maintain a certain Pace and Speed . . . . . 131 Change of Direction . . . . . . . . 133 The Gallop . . . . . . . . . . 136 Riding across Country and over Jumps . . . 137

\section{CHAPTER II}

RESISTANCES OF THE RIDING HORSE AND . HOW TO OVERCOME THEM . . 140

\section{APPENDIX}

EXAMPLE OF A "REPRISE" WHICH MIGHT SERVE AS A PREPARATION OF AN OFFICER'S CHARGER FOR THE CHAMPIONSHIP . . . . • . . . • 146 


\section{CAVALRY HORSEMANSHIP AND HORSE TRAINING}

\section{GENERALITIES}

OBJECT AND DIVISIONS.-The object of military cquitation is to turn out bold and skilled horsemen, exereising orer their horses a domination sufficiently complete to enable them to concentrate their whole mind, without effort, on their enemy, no matter what the circumstances, or the nature of the ground may be.

The instruction of horsemanship consequently comprises the practice of the systems taught to place a recruit on a horse; the study and use of the prineiples indispensable to the horsemanship of the older men, and the N.C.O.'s; and finally, the application of the rules adopted for the training of young horses. The study of military riding divides itself into three parts-

1. The education of the rider.

2. The education of the young horse.

3. The application of the principles of horsemanship and training to the employment of the horse.

First Part.-The Education of the Rider.-The education of the rider requires a trained horse. This part of the instruction includes the study of everything which specially concerns the man: it describes the qualities required in the instructor, and the method 
to be adopted in dereloping the aptitude of the rider. On the moral side it concerns itself with giving confidence, and on the physical side with the relaxing of the muscles. It lays down the best means of holding on, fixes the principles of the rider's position, as also those connected with the control and employment of the horse.

Training for these results demand the application of certain principles combined with much practice. Further, the teaching cannot be the same for erery degree of proficiency.

Elementary Equitation is that which is giren to young soldiers and only comprises instruction which is indispensable to a trooper.

Secondary Equitation is more particularly reserved for the instructors, who discover, by acquiring a thorough knowledge of their subject themselves, the advice to give to their N.C.O.'s and rough riders, and so complete their instruction. The object of this book is, to a great extent, to give them that knowledge.

The teaching of more adranced horsemanship is especially reserved for the officers, who, besides being proficient in all kinds of rough riding, must also acquire the refinement of the art, which is the object of the instruction given at the Cavalry School.

These teachings only differ from one another in their progressive extension, and in the more or less elementary or scientific methods required, according to the proficiency of the horseman; but they are founded on the same principles, tend to the same end, and together constitute the system of training, which is indispensable to the right employment and improvement of the cavalry. 
Second Part.-The Education of the Horse.-The education of the horse, on the other hand, requires a trained rider. This part deals with the examination of everything which coneerns the horse. On the moral side it studies his mental temperament, and the means for giving him confidence: on the physical side it deals with his constitution; getting him into condition; the laws of balance; and of animal locomotion; knowledge of which is essential for successful training.

Third Part.-Application of the Principles of Equitation and Training to the Employment of the Horse.-This chapter deals with the trained man riding the trained horse, and lays down the rules for their utilization in daily work.

Observation.-This aivision is in no way absolute; in practice a certain number of these questions commingle. Nevertheless, by assigning a place to ideas and facts, there is developed a clearness of vision, necessary in the wide field of horsemanship, which determines what effort should be made by the instructor and the rider, according as there is evidence of ignorance or awkwardness in the man or want of strength and a bad disposition in the horse. The cause of the trouble being thus located, the application of the remedy becomes more easy, and the effect more prompt. 


\section{FIRST PART}

\section{THE EDUCATION OF THE RIDER}

\section{CHAPTER I}

\section{ELEMENTARY HORSEMANSHIP}

\section{QUALITIES OF THE INSTRUCTOR.-Theoretical}

teaching without demonstration is foredoomed to failure. In teaching equitation, much therefore depends upon the instructor.

In addition to possessing the endowments of a good horseman, he should have great endurance, a high and strong character, and always set an example of correct bearing and exactness.

His speech must be devoted to imparting real knowledge, his words should be carefully weighed, and all misuse of language rigorously avoided: a man who is not master of himself is not worthy to command others. The instructor should be kind, and so encourage confidence; firm and decided in his demands; careful to avoid accidents; strong of nerve, so as to make a habit of audacity; patient and forbcaring with slowness of progress, and determined to overeome all difficulties.

In accordance with time and circumstances he should establish in his work a logical progression, conform strictly to rules and regulations, make sure 
of the regular stages which he has decided on, and retain the attention of his pupils by varying his teaching, so that each day brings a new and foreseen clement.

His own good scmse must mark the limits within which it is wise to continue the instruction, and help him to select a simple and fruitful course of procedure. The explanations he gives when mounted should be confined strietly to what is necessary, formulated with precision, and giren in such a way and in such a place, that every pupil can hear. He should never give explanations while working at the fast paees, but he must nerer let pass, without notice, any individual faults connected with position or the control of the horse: it is only by ineessantly criticizing the same faults that these can be eradicated.

Finally, the instructor should separate each difficulty he encounters into as many parts as are necessary to overcome them, conduct his work methodically in regulating his demands, and remember that progress is not the consequenee of the morement, but of the manner in whieh the morement is exeeuted.

The total of these direetions eonstitute the spirit of method. The spirit of method is the skeleton of instruetion; it is not its soul.

The instructor should, in the fertility of his mind and in the love of his profession, find expression to his ideas in words which will strike the imagination, amuse, persuade, and make his pupils keen.

Instruetion should be giren with good humour and dash; the even temper of the pupils, the frankness of their look, their intelligent zeal, and the love they have for the horse, are the marks of their confidenee and the measure of the rapidity of their progress. 
Still high above all these virtues which the instructor should possess, there is one which surpasses all the others, and which ought to illuminate his teaching : and that is the faith he has in his instruction. To transform a class of recruits into a troop of intelligent and keen horsemen, to train the brain and create in them the spirit of duty, of self-denial and of sacrifice, that is to say the military spirit, is surely a mission worthy of the exercise of the highest gifts and zeal of a leader of men.

What should be aimed at.- The objects to be kept in view in this first part of the instruction are: to give confidence to the horseman, to show him how to sit firmly on the horse, to bring him to acquire perfect control of his nerves, muscles, and limbs, and to give him the regulation position in the saddle.

Giving confidence to the horseman.-The instruction of the young soldier is hindered at first by the instinctive revolt of his nervous and muscular system, which causes contraction.

This universal defect is tackled by raulting, carried out cheerily; by conversations with the instructors, who take the men out on the leading rein for rides in the country - in a word, by distraction.

The particular contractions, which are experienced at the very commenecment of individual work, are soon made to disappear by the suppling cxercises laid down by the cavalry school.

So as not to neglect any of their useful effects, a consecutive order should be adopted, commencing with the seat, the loins, the shoulders, the arms and the head, and not undertaking movements of the thighs and legs until the body is thoroughly at its case. 'The best supplers, however, are good humour' 
and animation, which induee confidence promptly and definitely. To these onc should add compliments, which develop self-respeet, and in time self-reliancepowerful assistants in getting the best out of a horse.

As soon as a measure of eonfidenee has been obtained, the pupil should be shown the best means to employ to kecp himself in the saddle, i.e. by the seat and by the stirrups.

(a) The seat.-The seat is the quality which enables the rider to remain master of his balanee under every eireumstanee, no matter what reactions the horse may cause.

It is the prineipal quality to attain because it is the foundation of all good horsemanship, giving full confidenee and the assurance of good hands, without which neither the eontrol nor the training of the horse are possible. The seat is the result of a general decontraction, and in partieular the suppleness of the loins. It is prepared by earefully thought-out exereises of the joints, and is aequired on the lunging rein, by trotting and galloping without stirrups, and also by the number and varying eharacteristies of the horses ridden. This alone will make a man one with his horse, but a great amount of praetice is neeessary, and eare should be taken not to overdo the exercise and produce loss of skin and undue fatigue.

(b) The stirrups.-To rapidly give confidence to young horsemen, recourse must be made to another means of helping to keep them in the right plaee in the saddle, viz. by the use of the stirrups, which enable the learners to remain longer on horseback, and to proceed with their edueation without abrasions, and without hurt to the horse's mouth.

The trot without stirrups should be confincd to 
the riding school, or to short rides out of doors; that is, as a suppling exercise, and a proof of decontraction. All the work in the school, including jumping, should be carried out without stirrups, and, on the other hand, all long work out of doors, sword instruction and field work, active service, ete., should be done with stirrups.

Special gymnastic exercises.-Control of the "Reflexes." The reflexes are the nervous reactions, unconscious and involuntary, which arise in man from exterior impressions.

The control of the horse depends upon the independence of the aids, on which rests their future harmony. From the commencement of the preparatory work, one should accordingly make use of the exercises which the young soldier has to go through as a means of acquiring the elementary control of his reflexes, which the handling of the reins, when working with the bridoon and the bit, will enable him to completely obtain. The instructor concentrates his attention on securing-

(1) The independent action of the hands with regard to the movements of the body and legs.

To attain this result he teaches the bending of the body forward, backward, to the right, and to the left, and suppling exercises for the shoulders.

In all these movements the hand or the hands which hold the reins, should be held without stiffness in their proper position, in contact with the horse's mouth, but independent of the movement of the body. One should act in the same way in dealing with the legs and the clevation and rotation of the thighs; the bending of the legs should not in any way affect the horse's mouth. 
(2) The independenec of the hands and leges one ol another.

To obtain this liberty of the hands and legs the instruetor will put the rider through the suppling exereises, which tend to make the movements of the hands and legs independent of one another.

The most suitable movements to obtain this result are the movement of the arm backwards; patting the horse on the right quarter with the left hand, and on the left quarter with the right hand; the girthing and ungirthing of the horse when moving.

The instructor will take care in the execution of all these movements that the displacement of one part of the body does not affect any other part.

The results of these excreises are noticcable when the stride is lengthened in the trot without stirrups. If this exercise has been well directed, the joints acquire a suppleness and the limbs an independenee, of such a nature, that the reactions from the horse received by the spine have no effect on the rider's hands, which remain both fixed and light.

From the first it is necessary to make the rider understand the importance of these exercises. One should, moreover, watch that contact is never lost with the horse's mouth, and that exeessive force is not used. The endearour should be to give the rider the proper feeling of the horse's mouth. This feeling, as it develops little by little, will serve to establish the principle of stretehed reins, and of the elastic contact of the hand with the mouth. From the very first one should inculcate this principle and endeavour to attain its application.

The rider's position. - This is as laid down by the regulations. Its value results from the fact that 
the position which it gives to the hands and legs is that which permits them to act with the greatest promptitude, ì propos, intensity, and fineness.

Certain exercises supple the joints, bring about an improvement of physical defects, and overcome the contractions which arise therefrom. This general suppleness having been acquired, the instructor should derote his attention to placing the rider, then to fixing his position in all the paces, on varying types of horses, and on different kinds of ground.

When the instructor commences to occupy himself with the man's position, he takes adrantage of the first ride at the walk to place individually every man, before starting the trot. Immediately the positions cease to be correct, the horses should be brought back to the walk, the men put back into position, and the trot restarted: from this method arises the necessity of at first having short but frequent trots. It is by proceeding thus that a good seat is obtained.

Firmmess of seat is the absence of all involuntary or useless movements, and the reduction to what is strictly necessary of those which are indispensable. It allows the aids to be applied with precision and lightness, and consequently brings steadiness to the horse, while contributing to his lightness.

It must be quite understood that regularity of position must give way to the necessity of adapting oneself to the horse's movements.

To be with the horse is the first of all qualities of a horseman, and to be well placed, as a general rulc, leads to the rider becoming one with the horse.

The good position of the rider depends principally on the direction in which he looks and how he places his hands, his thighs, and his knees. 
(a) The fact that the eyes should be active and looking straight to the front makes it necessary for the rider to hold his head high, to straighten his body, and to bring his seat well under him. More than this, from the first the men get into the habit of observing what happens around them, which is the duty of a cavalry soldier.

(b) If the hands are well plaeed, separated, and the nails facing one another, the elbows are naturally close to the body, in consequence of which the shoulders are pressed back, the chest is pressed forward, and the head is raised with an air of ease.

On the other hand, if the nails are downwards, the elbows stick out, the shoulders come forward and close in the chest, the head follows the movement of the shoulders, and the eyes fall, whilst the seat tends to slip backwards.

(c) The seat results from the position of the buttocks; they should be as far forward as possible, without causing an exaggerated pressing down of the backbone.

(d) If the knees are well turned in, the muscles of the thighs find their place under the bone, which fits in a natural position, flat against the saddle. The placing of the knee regulates that of the foot which assumes a normal position.

To sum up, the soldier should hold his head high, and present, in his general attitude, straightness without stiffness, and suppleness without slackness.

The Suppling Exercises.-It is obvious from what has been stated that the suppling exercises play a very important rôle in the instruction of the horseman, and also that their employment demands peculiar taet. Used without order and method by 
some instructors, they only give but moderate results, but when employed correctly they transform into horsemen happily and very quickly, even those with the least natural aptitude. Taken as a whole, the suppling exercises have a triple effect. They serve to obtain--.

(1) General decontraction.

(2) The independence of the aids.

(3) Regularity of position.

The instructor groups and utilizes the suppling exercises which seem to him the best to attain the end he has in view.

In the first two cases the suppling excreises affect all the men in the ride, since the instructor has a uniform object in view. In the last case it is right, on the contrary, to prescribe to each horseman the special exercise which he should do.

One should notice, moreover, that certain of these movements are contrary to one another, and that it is necessary when employing them to know exactly the end one wishes to attain, e.g. the raising of the thighs, particularly favourable to the acquisition of the seat, evidently counteracts the benefit of the revolving of the thigh, intended to put it on the flat side, and to cause the leg to drop. At the end of a few weeks of well-regulated instruction, confidence is established, the contractions diminish, the riders commence to find and keep the bottom of the saddle, their joints aequire frecdom, and in consequence they obtain greater control over their morements. It is then time to consider the question of horse control and to lay down the principle gorcrning it. 


\section{CHAPTER II}

SECONDARY EQUITATION

HORSE CONTROL

True prineiples and the system of eontrol indispensable to the ordinary soldier are explained in the drill book, and constitute elementary horsemanship. The following concerns more especially officers, and constitutes secondary equitation.

The art of horsemanship teaches how to use the means at the rider's disposal for managing his horse at all paces, and on all kinds of ground.

To control a horse is-

(1) To put him in morement.

(2) To regulate this movement.

(3) To direct this movement.

Though simple in theory the management of the horse is none the less complex and diffieult in practice. It demands a knowledge of all the resources that art and science can place at our disposal.

It is necessary, in the next place, to be able to dispose of these means as one wishes; in fact, oncness with the horse demands from the rider the accurate employment of his means of action.

To sum up, it is necessary-

(1) To understand the means of action.

(Study of the aids.) 
(2) To be master of the means of action. (The discipline of the aids.)

(3) To know how to utilize these means of action. (Employment of the aids.)

The knowledge and the application of these three fundamental rules are indispensable in the making of a horseman, but their study in no way lessens the preponderant part which practice always plays. Practice without theory is always uncertain, and the application of good principles alone secures the perfect utilization of the horse.

\section{To Understand the Means of Action}

\section{Knowledge}

STUDY OF THE AIDS.-The knowledge of the aids, looked at as a whole, requires the examination of the physical aptitudes and moral qualities of the man, the study of the properly called natural aids, and the knowledge of the artificial aids.

Value of the moral qualities and the physical aptitudes. -The weight, the figure, the firmmess or slackness, the muscular power or the want of strength, the suppleness or stiffness, the energy or the lack of it, the intelligence, and the patience, or, on the contrary, the apprehension, the nervousness, and the brutal nature of the man, are factors in equitation which seriously influence results, no matter how excellent the instructors or their methods. All this should be carefully considered in assigning horses to the riders, more especially if the former are young.

Natural aids.-These are the legs, the reins, and the weight of the body. The legs and the reins serve to put the rider in contact with his horse; they 
enable him immediately to judge the character, temperament, and state of training of the horse, and then to transmit and impose his will upon it. The movements of the horse vary according to the position taken by the various parts of his body, and according to the degree of impulsion of which he has the disposal. In order to cause the horse to exceute any movement, it is necessary both to give him a position which allows, makes easy, or determines the movement which one wishes, and to produce, maintain, inerease or lessen the impulsion.

The rapidity of movement depends upon the degree of impulsion. It is by means of the aids that there is given to the horse position and impulsion.

The action of the legs. - The legs of the rider should be fixed, that is to say adherent, and in light contact with the body of the horse, free from all involuntary movement; any action should be hardly noticeable, and the length of the stirrup leathers should be adapted to this end. In this case as in that of the seat, the opposite of fixity is a swinging morement which upsets the horse. The legs can act, resist, or yield. They act when their pressure increases to bring about a movement; they resist when their pressure is meant to limit or prevent a displacement of the hind quarters, they yield when the pressure deereases and allows of this displacement. In the first two cases they are aetive in different degrees; in the third case they are passive.

(a) When the two legs act together they should have the effect of driving the horse forward, if he is standing, or of increasing the impulsion if he is in movement. Their action should take effect near the girths, gently so as not to surprise the horse, 
energetically and by decided intermittent pressure of the calves if he hesitates to go forward.

(b) When one leg only, the right for instance, acts behind the girths, it should have the effect whilst causing forward movement to push the quarters to the left. The horse looks to the right if he is standing and moves forward, turns to the right whilst increasing his pace if he is moving. This action is produced by drawing back the heel slightly and progressively, so as not to surprise the horse; by intermittent pressure of the calves if he hesitates to yield, and by removing all pressure the moment he obeys.

(c) The right leg acting against the girth, when the left leg prevents the displacement of the quarters, will have the effect of bending the horse to the right and of bringing the right hind leg under the body. This action of the leg should be employed when the horse is standing: it requires great tact and belongs rather to the high school of riding.

The spur serves on occasions to strengthen the action of the leg and to render the obedience of the horse more prompt. It is to the leg, what the curb is to the hand. It should be used with discretion, in accordance with the desired results, and the horse's sensibility. A distinetion, however, should be drawn between the energetic pressures intended to force the horse forwards or to punish him, and the quick, light touch of the spur which is one of the fine aids.

Action of the reins. - The reins act on the horse's mouth by means of the bits. In order that this effect may be accurate, they must be held at a right length and stretched during work: if they are slack the indications of the hand will not reach the horse, or they will be confused, or perhaps, in the form of "jobs," 
be both brutal and clumsy. One calls "contact" the elastic correspondence which ought to exist betwe'n the rider's hand and the horse's mouth; in the case of some horses-in particular young ones-the contact is a steady equal fecling; out of doors at the last paces, and especially in a charege, the contact can become a support more or less strong.

The hands, like the legs, can act, resist, or yield.'The reins being adjusted the hands act when they increase the tension of the reins; they resist when they fix themselves; they yield when they follow the morement of the neck. It is very important to know how to act, resist, and yield, at the right moment. The actions of the hands should be progressive. The hand which resists has a very powerful effect without irritating the horse, as an active pulling would: it produces its effect by reason of its firmness, and it should yicld the moment the horse obeys.

An actize hand is one which acts on the equilibrium or on the impulsion; a passive hand is one which, whilst preserving the contact, does not oppose either the impulsion or the displacement of weight.

The many and diverse sensations and resistances, transmitted by the reins to the hand of the rider, have consequently necessitated the variety of the actions of this hand. Amongst these numerous actions, it is necessary to determine and define those, of which the simple and evident effects suffice to obtain all the morements useful in military equitation.

\section{A. The Reins Regulate the Impulsion}

The two reins acting together should have the effect of decreasing the pace, stopping the horsc, or 
of making him back. They are called direct reins. Their action is produced by fixing the hands, the fingers being closed on the reins held at a proper length, whilst the elbows and hands are drawn back as little as possible.

'The half halt is a strong and briel action of the hand, which the rider carries out by closing the fingers on the reins and turning the nails quickly upwards without losing touch with the horse's mouth; the hand being carried slightly back. It serves to steady excitable horses, and also to carry back to the hind quarters the excess of weight which some badly balaneed horses carry on their forehand. It is given, according to necessity, either with one rein, or with the two reins together, and either with the bridoon or the bit reins. The hand should proportion the force of these effects to the amount of resistance which the weight offers.

The vibration is a succession of slight jerks, communicated to one of the bits through either one rein, or the two reins at the same time. It can be giren, as in the case of the half-halt, with the bridoon or the bit reins; it is continued for a few seconds, and is strong or light, according to the resistance encountered. This action is used to overcome the muscular contraction of the lower jaw, which the horse opposes, either instinctively or voluntarily, to the action of the bit.

B. The Hands also give the Position to the FOREHAND

'The reins act by the mouth, on the head, the neck and the shoulders. 'They emable the rider to place the head in relation to the neck, the neck in relation to the 
shoulders, and the shoulders in relation to the quarters. They can cren act indirectly on the quarters, by giving to the shoulders a position which obliges the quarters to change their direction, i.e. they oppose the shoulders to the quarters.

'These different effects depend upon the direcetion given to the tension on the rein, aceording as the hand is carried more or less forward or backward, more or less to the right or left, more or less upwards or downwards.

The various actions of the hand can be grouped in five main series, but this is a purely theorctical division, which helps in the study and application of the aids. Between these extreme actions, forward to the right, backward to the right, backward to the left, and forward to the left, there are numberless directions, or tensions, which form as it were a keyboard, on which the rider will find the right note all the more quickly in aceordance with his knowledge, experienee, and

\section{ERRATA.}

der

On page 18, second paragraph, first line, the word the " jerks" should read "shakes."

ned

oll

(b) If the rider inereases the movement of the right hand towards the right, the neek follows the head, the shoulders follow the neck, and the horse looks to the right, whilst advancing.

2. By giving to the right opened rein a backward tension, the rider draws his horse's shoulders backwards and to the right, and forees him to throw his quarters to the left. The rein is now ealled the direct rein of opposition. 'This action is produced by lowering the 
of making him back. They are called direct reins. Their action is produced by fixing the hands, the fingers being closed on the reins held at a proper length, whilst the elbows and hands are drawn back as little as possible.

The half halt is a strong and brief action of the hand, which the rider carries out by closing the fingers on the reins and turning the nails quickly upwards without losing touch with the horse's mouth; the hand being carried slightly back. It serves to steady excitable horses, and also to carry back to the hind quarters the excess of weight which some badly balanced horses carry on their forehand. It is given, according to necessity, either with one rein, or with the two reins together, and either with the bridoon or the bit reins. The hand should proportion the force of these effects to the amount of resistance which the weight offers.

The vibration is a succession of slight jerks, comm

o?

a

$\mathrm{b}$

st

$\mathrm{T}$

tion of the lower jaw, which the horse opposes, either instinctively or voluntarily, to the action of the bit.

B. The Hands also give the Position to the Forehand

The reins act by the mouth, on the head, the neck and the shoulders. They cnable the rider to place the head in relation to the neck, the neck in relation to the 
shoulders, and the shoulders in relation to the quarter's. They can cren act indircetly on the quarters, by giving to the shoulders a position which obliges the quarters to change their direction, i.e. they oppose the shoulders to the quarters.

These different effects depend upon the direction given to the tension on the rein, according as the hand is carried more or less forward or backward, more or less to the right or lelt, more or less upwards or downwards.

The rarious actions of the hand can be grouped in five main series, but this is a purely theoretical division, which helps in the study and application of the aids. Between these extreme actions, forward to the right, backward to the right, backward to the left, and forward to the left, there are numberless directions, or tensions, which form as it were a keyboard, on which the rider will find the right note all the more quickly in accordance with his knowledge, experience, and tact.

1. (a) In earrying the hand to the right, the rider displaces the head of the horse towards the right; the right rein in this ease takes the name of the "opened rein." The rider should avoid pulling backwards on the rein and moving his elbow from the side.

(b) If the rider increases the morement of the right hand towards the right, the neck follows the head, the shoulders follow the neek, and the horse looks to the right, whilst advancing.

2. By giving to the right opened rein a backward tension, the rider draws his horse's shoulders backwards and to the right, and forees him to throw his quarters to the lel't. 'The rein is now ealled the direct rein of opposition. This action is produced by lowering the 
hand, the fingers being closed on a rein of proper length.

3. (a) By carrying the right hand forward and to the left, the rider draws the horse's nose to the right, and places on to the left shoulder the greater part of the weight of the neck. The right rein is then called the contrary or indirect rein.

(b) If the rider inercases the movement of the right hand towards the left, the resulting increase of weight will cause a displacement of balance towards the left, and the horse will turn to that side, the turn being made whilst advancing. By giving to the indirect rein (right rein) a backward tension, two effects can be produced, according as the tension of the rein is applied in front of or behind the withers.

4. If it is applied in front of the withers, i.e. towards the near shoulder, the shoulders are brought back to the left, the horse faces to the left, and moves backwards, if he is stationary; he turns to the left, slackening his pace, if he is in movement.

5. If the rein is drawn across behind the withers, i.e. towards the near hind leg, the rein acts on the whole horse, and pushes both the forehand and hind quarters to the left. If the horse is moving, this diagonal action of the right rein, whilst bending him to the right, pushes him obliquely forward towards the left, and with all the greater energy if the impulsion is great.

The two actions (4 and 5) of an indirect rein both tend to oppose the shoulders to the quarters and take the name of "contrary opposing reins" or "indirect rein of opposition."

Harmony of the aids.-The harmony of the aids is the co-operation that the rider should obtain from 
the legs, the hands, and the weight of his body, in order to bring about, make casy, or hasten the proper execution of the required movement.

1. Harmony between the legs acting together and both reins acting together.

The legs give the impulsion.

The reins regulate the impulsion.

The simultancous action of both legs has the effect of causing, maintaining, or increasing the forward movement.

The simultaneous tension of both reins limits the forward movement, i.e. it decreases the pace, stops or causes the horse to go backward. These two actions are totally opposed to one another, and should never be employed at the same time, under penalty of destroying all impulsion. When the legs act to produce an increase in the pace, the hands should yield, and should resist if it is necessary to restrain the horse. In the same way when the reins act to reduce the pace, the legs yield, then resist, if it is necessary to limit the slackening of the speed.

To sum up, if it is a matter of reducing speed, stopping, or of going backwards, the legs regulate the movement when necessary, but they should not act till the horse has commenced to stop, or if he stops too suddenly. If it is a question of starting the walk, of taking the trot, or of lengthening the stricle, the reins should be ready to resist at the right moment, to regulate the pace, but they should not have any effect until the horse has commeneed to yield to the pressure of the legs. When going straight forward the action of the hands and the action of the legs are, therefore, never simultaneous. It is evident that the better the horse is trained, the more obedient he is, the more 
one can combine these actions without mixing them up. On the other hand, the more undecided the horse is, the clearer ought to be the indications given him, and the more necessary it is to separate the actions, so that they may not counteract each other.

2. Harmony of the two reins.-Before trying to regulate or strengthen the action of one rein by that of the other, it is neeessary to make certain that they do not oppose one another; if the right hand acts, one must see that the left hand allows the action of the right hand to produce its full effect. Accordingly, not only should the left hand refrain from acting, but it should not even resist : it should yield.

If it acted at the same time as the right hand, even if it resisted, so far from strengthening the action, it would but oppose, lessen, or perhaps completely destroy it. To yield the left hand, when the right hand acts, is to give to the action of the hand its full cffect.

To sum up, each time that the right hand acts, whether it be by opening the rein, by applying the direct rein of opposition, the indirect rein, or the indirect rein of opposition, the left hand should first yield, to allow the head and ncek to take the indicated position, then resist, if it is necessary to limit the movement, in which case it plays the part of a regulating rein. An action of the left hand can perfectly follow the action of the right hand; one can substitute. for example, an action of the indirect rein for the action of the opened rein, but these actions are alternative, and the principle of the actice rein and of the passive rein is always observed. When riding with one hand, the indirect rein acts alone, the direct rein becoming slack at the moment of action. If the two reins are 
not in absolute agreement, they, at any rate, do not oppose one another.

3. Harmony of the legs.-When the right leg alone acts, the left leg should first yield, so as to allow the action of the right leg to produce its effect; it resists, if necessary, to regulate the morement, by limiting the displacement of the quarters.

4. Harmony of the legs with each of the effects of the reins.--The pressure of the legs causes the horse to move forward, and produces the movement, which the rein should direct; in the same way the tension of the reins aims at producing on the quarters, effects which the legs should assist. There is consequently a constant co-operation between the legs and the hands, which, instead of opposing one another, should, on the contrary, combine, harmonize, and strengthen their effects.

(a)* The right opened rein earries the weight of the neck on to the right shoulder, without opposing it to the quarters, which follow the direction taken by the shoulders. The legs merely maintain the movement by an equal pressure.

(b) 'The right rein direct of opposition bends the neck to the right, by bringing the weight on to the right shoulder, so as to oppose it to the quarters and foree them to the left. 'The right leg should assist by also foreing the quarters to the left.

(c) The right indirect rein causes the head to swing to the left, places the weight of the neck on to the left shoulder, without opposing it to the quarters. Both legs act equally to maintain the forward movement.

(d) The right indirect rein of opposition (drawn across in front of the withers) bends the neck to the right, earries the weight on to the left shoulder, and

* See diagrams, pp. 25-33. 
throws the quarters to the right, by opposing the shoulders to them. The left leg also presses the quarters to the right.

(e) The right indirect rein of opposition (drawn across behind the withers), by bending the neck to the right, has the effect of carrying the weight on to the left shoulder and quarter, and draws, when the horse is moving, all the weight forward, and to the left, by opposing the head and the neck to the shoulders and quarters.

The right leg by pressing the quarters towards the left, strengthens and increases the movement, which the left leg acting against the girths also maintains.

It must be well understood that in recommending the action of one leg, it is not implied that the other should remain inactive; it should, on the contrary, keep up and regulate the impulsion, as has been said before when speaking of the harmony of the legs.

Weight of the body.-In studying the action of the reins, it has become evident that under their influence the balance of the horse is affected to the extent of turning him either to the right or left, according as the weight of the neck is carried on to one or other of the shoulders. The shoulders unequally weighted turn to the side on which the excess of weight inclines them.

The distribution, equal or unequal, of the weight of the horse on to the limbs, which support it, has a direct influenee in imparting a line of morement to the whole body.

When the horse is mounted, the mass which the legs sustain is not wholly comprised in the weight of the horse itself ; it is necessary to add also that of the horseman, the upper part of whose body in displacing 
a. FIRST EFFECT (LATERAL).

The Opened Right Direct Rein.

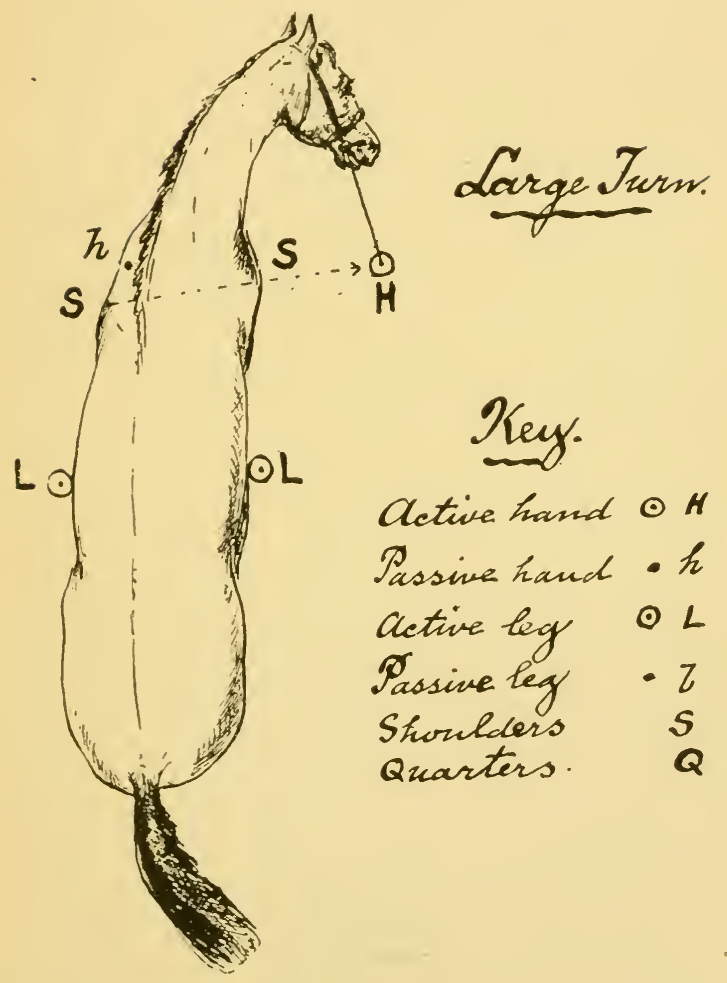



b. SECOND EFFECT (LATERAL). Right Direct Opposing Rein.

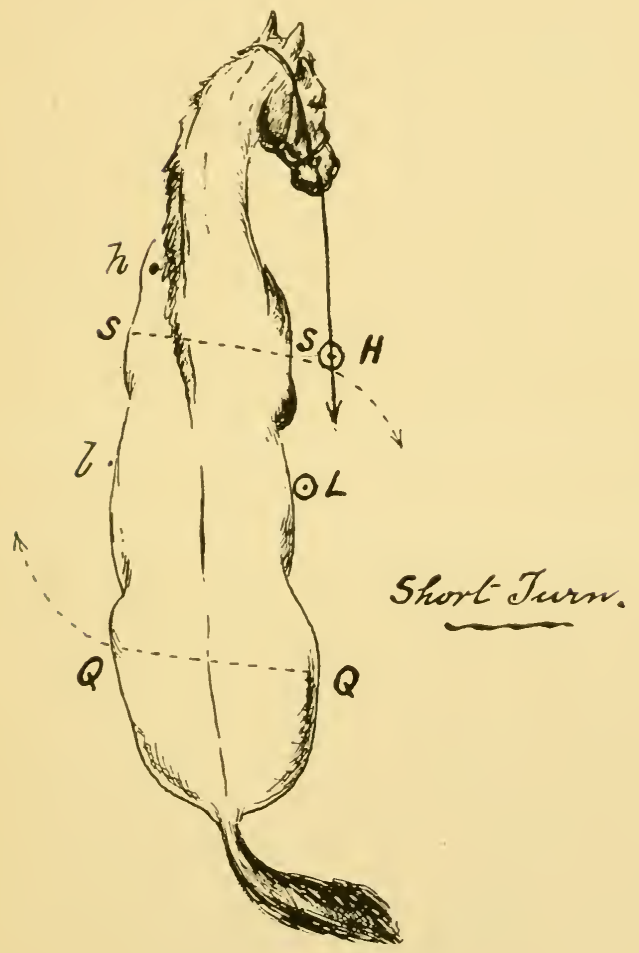



c. THIRD EFFECT (DIAGCNAL . RIGHT INDIRECT REIN.

Lange Tum.
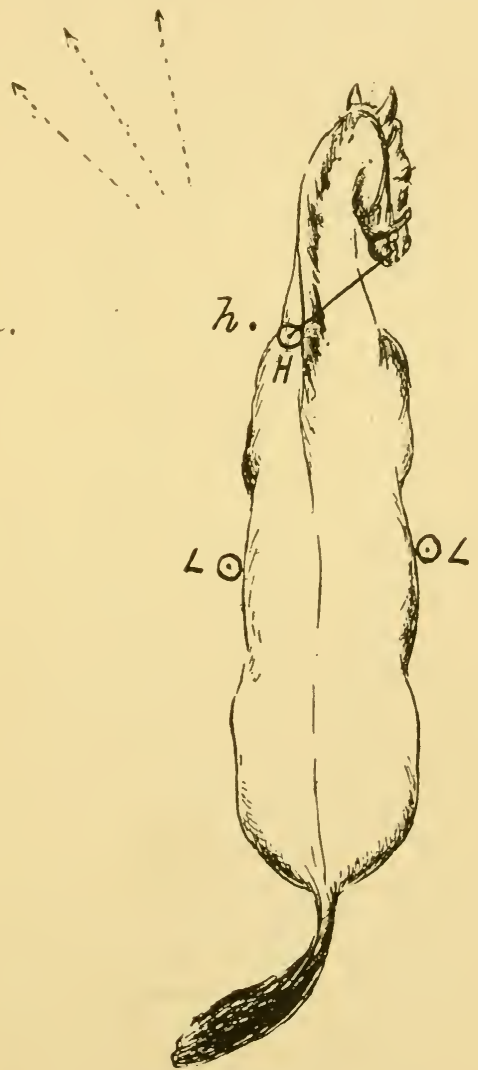

d. FOURTH EFFECT (DiAgONAL).

Rigit Indirect Opposing Rein.

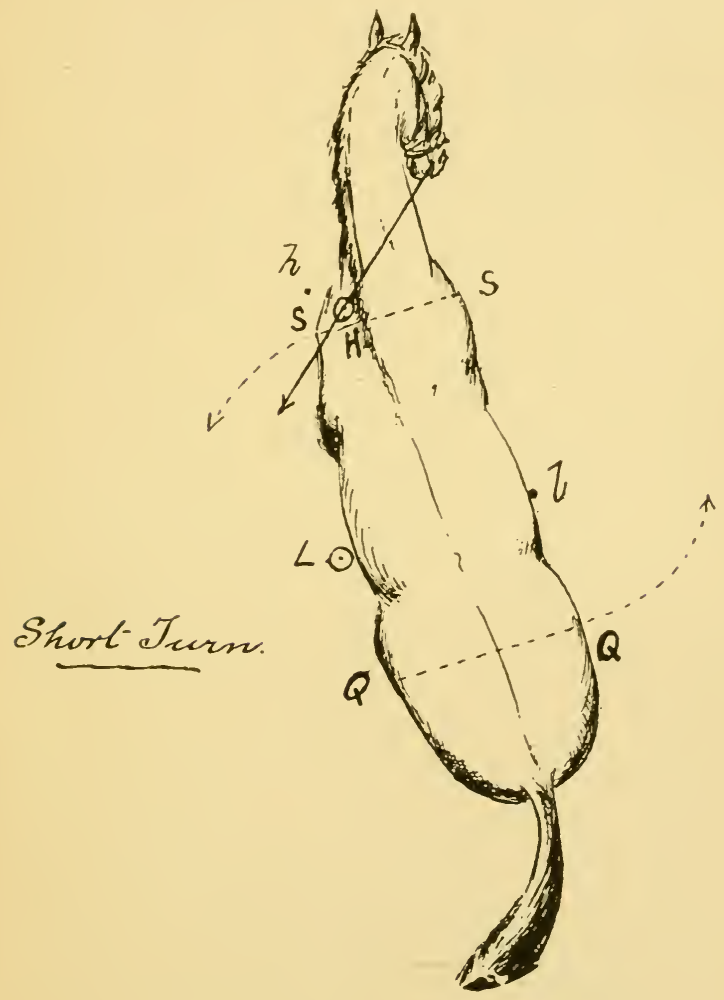



e. FIFTH EFFECT (DIAGONAL).

Right Indirect Opposing Rein.

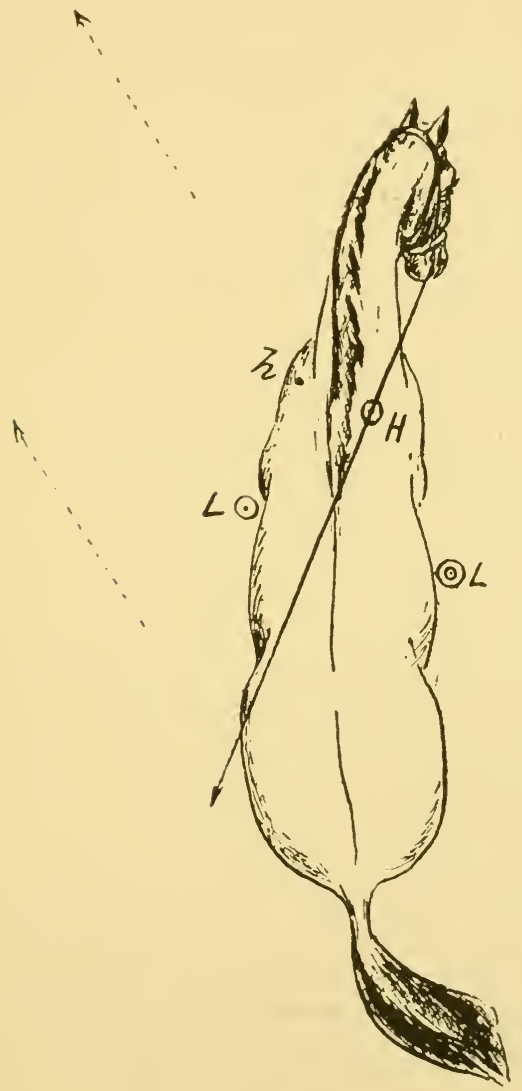



itsclf contributes greatly to the modifications which the aids bring about in the balanee of the horse. It is accordingly necessary to warn the rider not to oppose the morements of the horse by a bad distribution of his own weight, but, on the contrary, to assist them by placing his weight so as to favour the direction desired. In the walk, in the halt, in turning, and in the side morements, the rider, by carrying his weight on to the buttocks or thighs in the direction of the movement, can accordingly simplify and hasten the obedience of the horse. Whilst sufficiently clearly marked in the breaking of young horses, these displacements of the seat should become less and less marked as the training advanees, and in the High School of Riding it reduces itsclf to simple pressure on the stirrup.

Lateral and diagonal aids-Lateral and diagonal effects. - In instruction, in order to shorten the explanations, the aids should be considered either from the point of view of the various combinations, which result from the association of both hands and both legs, or from the point of view of the direction of their action, that is to say, of the effects produced.

When the determining aids are applied on the same side of the horse, for example the right leg and the right rein, they are called lateral aids. When, on the other hand, one is applied on the right side and the other on the left side of the horse, for example the left leg and the right rein, they are called diagonal aids.

If one considers the direction in which the reins act, lateral effect describes every action of the hand, right, for example, acting on the right side of the horse; e.g. direct rein-opened rein-and the direct rein of opposition. On the other hand, diagonal effect includes every action of the hand, right, for example, 
acting at the same time backwards and from right to left (actions indirect and indirect of opposition).

In accordance with these definitions, if when moving sideways to the right, the rider makes principal use of his left leg and the left rein, he cmploys the lateral aids; but the left hand acting backwards and from left to right produces a diagonal effect.

If in the same norement the rider employs principally the left leg and right rein he uses the diagonal aids; but the right rein, in drawing the horse's head slightly into the direction of movement, produces a lateral effect.

These remarks show how more apparent than real are the distinctions drawn by certain writers between lateral and diagonal horsemanship. True horsemanship is nothing but the combination of all the aids, and of all the effects, lateral or diagonal, which we have just mentioned. The rider has two hands and two legs which can act separately or together, laterally or diagonally, and thus produce rarious effects. It is for the rider to use, according to the horse he is riding, or the end he has in view, the aid or the aids which should produce the desired effect.

Artificial aids.-The whip, martingales, nose bands, the dumb jockey, etc. These different aids may be invaluable, when first breaking a horse, to rapidly regain lost authority, or to give some difficult subjects the work necessary for their training, but it must not be forgotten that most of these means, excellent in certain hands, become dangerous when used by inexperienced horsemen. Besides, the results, obtained perhaps very rapidly by means of these aids, are as a rule superficial, they ean therefore only supplement the true education of the hor'se, which 
consists as much in moral submission, as in physical obedienee to the natural aids.

\section{II.-Self-CoNtrol \\ Poxer}

The discipline of the aids.-IIowever exact theoretically the effects of the legs and reins may be, their effects can only have practical utility, if the aids which produce them are perfectly disciplined, and under the control of the rider's will. In horsemanship you must not only know what to do, but you must be able to do it.

'The eontrol, which we must exercise orer our means of making ourselves master of our horses, demands, before everything, the control of the moral forces mentioned in the preceding chapter. Calmness, patience, and coolness, amid difficulties, are all qualities indispensable to the right practice of horsemanship. It is often the case that a horse is disobedient because the moral of the rider is not in its normal balance. The absolute independence of the aids (legs, hands, and the weight of the body) is none the less important to acquire, because it alone will develop their neeessary harmony.

Our organism makes the free play of our limbs difficult, and to be of use the most simple movements require an apprenticeship.

If, for example, you tell a young horseman to close in the left leg, you will see nearly always the right leg automatically remore itself from the saddle to a distance equal to the morement of the left leg.

An impartial examination reveals, eren in the ease of the best horseman, faults daily committed in the 
control of the horse. If the horse does not readily obey, it is not generally owing to ignorance or bad temper on his part; it is because the aids, misapplied, are powerless to transmit the rider's wishes, and do not indicate the desired movement.

Dexterity and awkwardness.- Since the control of the nerres, muscles and limbs, is one of the keys of equitation, it is of the greatest importance that the instructors should know the scientific causes of what one commonly calls awkwardness.

In a limb, one half of the muscles are intended to act in one direction, and the other half in an opposite direction.

In nearly all movements these antagonistic muscles come naturally into play, and their conflict causes, in the limb, an immobility which is far from being repose, and is what is called contraction or stiffness. This contraction does not confine itself to the limb in which it started; it develops in other parts of the body, where it produces disorder, and either interferes with the movement or gives rise to what is useless. The forces thus lost, or which become harmful, are considerable. The recruit, when his horse is out of control, brings into play, without stopping him, the power of his usclessly contracted shoulder muscles, whereas by making use of his fingers only on the reins, he would have stopped him casily: this is waste of energy.

It is therefore indispensable that the horseman, like the marksman, should train his museles by exercise.

In the preparatory work, from the carlicst instruction on horseback, one tries by a series of appropriate suppling excreises to make the application of the aids, 
as it were, more delicate; to give to the hands and legs an independence relative to the movement of the body of the man, and of the horse ; but the results obtained are nerertheless mostly negative, a sort of incrtia. What we are concerned with obtaining now, is an independence, productive of energy, giving the aids an active intelligence, and, later on, bringing about the desired morement.

The work of the instructor who has arrived at this stage of training, consists in making and multiplying for the young horseman oceasions for the employment of the aids, and in teaching him to apply them in an exact and precise manner, separately at first, and then in combination.

(a) The pupil, holding the reins separated in the two hands, is told to use, in simple movements, firstly the effects of opening the rein, then the effects of the indirect rein, followed by the opposition effects, whilst completely slackening the rein which does not determine the morement.

Example :-

"By the right opened rein, turn to the right."

"By the indirect right rein, turn sharply to the left."

"By the left direct rein of opposition, half turn to the left," etc., ctc.

(b) IIe is then taught, in combined movements, to substitute the effects of opening the rein for the effects of opposition, or indircet effects for the effects of opening the direct rein.

(c) When this exercise of the hands separately is well understood, and well done, one should teach, with the same morements, and with the same progression, the use of both rcins, brought into harmony, 
the hands acting, resisting and yielding, according to circumstances.

(d) Then make the movements complicated and at fast paces, so as to give to the hands decision and quickness.

In the midst of these growing difficulties, the instructor should satisfy himself that the rider rightly uses all the action of hands and legs which are ordered, and that he understands the effects, which are the consequence. The instructor also shows the position of the head and neck to be aimed at, the faults to aroid, and will correct incessantly all the faults committed.

It is by a series of exereises for the hands and legs, executed with a definite end in view, that the muscular feeling, indispensable to the proper control of the horse, is developed. Skill takes the place of the early awkwardness, and the rider has only to acquire the tact, which is the result of experience, to enter into full possession of all his means of controlling the horse, and to orercome all difficulties as they present themselves.

\section{III.-Tine Proper Use of Energy}

\section{The Will}

Employment of the aids.-When the rider knows his powers, and is master of them, it remains for him to decide on their employment, and to use them tactfully.

Equestrian tact, which has been defined as moderation plus it propos, is the sense which watches over the cconomical use of the powers of the horse and of the rider; it brings the latter to determine the effect he wishes to produce, the intensity of this effect, and 
the right moment to try for it. It cnables him to orercome resistances if they occur, or better still, to prevent them.

The agents of equestrian tact are the seat, the legs, and the hands.

The seat.-The seat, of which the importance has been deseribed throughout from the point of view of giving recruits confidenec, plays an equally important rôle, in sceondary equitation, in the art of horse control. It is in effect the seat which enables the rider to acquire the feeling of the mechanism of the paces, to perceive a great part of the contractions of the horse, and in particular the resistances and submission of the hindquarters, the seat of the impulsive forces. Morcover, the firmness and confidence; which the seat gives to the rider, alone allow of his using his aids independently and employing them accurately, as taught in the preparatory work; the seat should be constantly improved and maintained during the whole time the man is in military service.

Right use of the legs.-The legs can only act in one way, but there is in their use a question of à propos and also a question of intensity, which the spur will render still more energetic, and which demands, both in the case of the legs and spurs, a real delicacy. The rider by his seat and by his legs, can acquire a certain feeling of the movements, howerer fugitive they may be, which constitute the raising, the suspension, and the placing down, of the legs; he can therefore profit by it to hasten or lessen the action of the legs, and to annul in consequence their combination, and so rectify and modify the paces.

Qualities of the hand.-The study of the action of the reins has well marked their theoretical effects, 
but these effects produce results very different, according to the quality or defects of the hand which causes them.

The qualities of the good hand are fixity, lightness, gentleness, and firmness.

To have the hand fixed, does not mean that the hand should remain motionless in its position; it should, on the contrary, in accordance with the necessity, carry itself upwards, to the right, or left, but in the execution it should be free from all involuntary or useless morements.

This quality is the first to seareh for, and the most important of all; without it the others will not be able to show themselves in their fullness. The uncertain hand, which is the opposite of the fixed decided hand, can neither have lightness, gentleness nor firmness, and the most attentive horse is unable to obey its ill-regulated actions.

The light hand feels the simple eontact with the mouth.

The gentle hand gives support.

The firm hand gives a decided support. 'The hand should also know how to resist with firmness when necessary, and to yield the moment the resistance ceases, then return to gentleness, which is always the touch of union between lightness and firmness. It is in this sense that one has been able to define the good hand, as having in the fingers a force equal to the resistanees of the horse, but never superior to thenı.

If at first, the hand, the wrist, and forearm, take part in the action, when riding a trained horse, it is solely by the elosing more or less strongly of the fingers, or the more or less loosening of their hold on the reins, that the rider transmits his wishes to the horse. 


\section{CHAPTER III \\ SUPERIOR EQUITATION}

EDUCATION OF TIEE OFFICER

THE superior school of horsemanship is merely the normal development and the exact application of the principles which serve as the basis of all horsemanship. It teaches the officer to preserve eren in the midst of the greatest difficulties, a perfect and firm seat, with justice and fineness in the application of his aids, combined with an absolute discretion in their employment. It teaches, in fact, the ease and correctness of position, which proves the control of the rider orer himself and the clear free working of his mind. It searches for eonstant forward impulsion in the horse, calm absolute obedience, and a position rigorously straight and balaneed, in the execution of all movements.

Without considering the teaching of the Maute École, the higher education borrows from scientifie horsemanship the use of eertain of its airs, such as the classical movements to one side, the changing of the leading leg in the canter, and we might add the passage morements which show in the horse an extra degree of submission to the aids, whilst at the same time they develop, to the greatest degree, tact and the 
sentiment of the horse, in the rider. By insisting, both in the case of the horse and of the rider, on sobriety of morements and gestures, perfection of balance, and grace of attitude, the superior school of horsemanship has done much to produee the reputation enjoyed by the French School. The qualities which it develops, are a powerful element in diseipline, because they increase the prestige of the instruetor, and strengthen his authority, by showing his unvarying superiority in the daily work of his command. 


\section{SECOND PAR'T \\ 'IHE EDUGA'TION OF 'THE HORSE}

\section{CHAP'TEL I}

THE QUALITIES OF A SADDLE HORSE.-'The many demands made on an army horse require in him a great many different qualities. He has to earry a considerable weight, * travel long distances, and often at a fast pace ; he has therefore to possess endurance, hardiness, and handiness. These qualities are nearly always found in a horse which has a naturally good balance, good paces, breeding, and conformation. The naturally good balance, which is the first quality to look for in a riding horse, enables him to have constant control of himself, even with the weight of a rider on his back, to easily change from a slow pace to a fast one and vice versî́; to be, in fact, supple in his morements, and easy to ride from the first. The theory of balance has not up to now been scientifically considered; owing to the rapidity and frequency of a horse's morements, the study of balance or of conformation is practically limited to the study of the animal at rest. Anatomy is nothing but the study of organs from which life has been withdrawn. It is therefore

* In the British Cavalry a man, weighing 10 stone $7 \mathrm{llbs}$. stripped, rides no less than 21 stone, in full marching order. 
only by riding a horse, that one can with any certainty decide on his merits. Experience, nevertheless, enables one to establish certain general rules, which fix the good points to be looked for in a young horse, and to form an opinion as to what he will grow into.

If the horse has a wither running well into the back and rather higher than the quarters, the chest deep, and the girth groove well behind the elbows, the saddle will rest in a good position. The rider and his equipment being placed between the two ends of the balance, near the centre of gravity, will not disturb the equilibrium by overweighting the shoulders. This conformation, combined with well-shaped hocks, causes the horse to be easy to handle and control in a fight, and in the daily work the effort is distributed over the body, which consequently does not prematurely wear out. The paces ought to be such as will enable the horse to cover the greatest distance with the minimum of effort. This condition excludes high action, and places value on the level extended paces, which are the least fatiguing for both horse and rider.

If the trot is more especially the pace for the road, the pace for fighting is the gallop. More than ever the actual necessities of war require the fast paces maintained for long distances. The army horse ought therefore to be above everything a galloper, and the relative length of the ischium is a characteristic of this aptitude.

Handiness is indispensable in going through evolutions in open country, and it is acquired all the more promptly and completely in proportion as the horse has the necessary conformation, an open angle at the junction of the shoulder and arm, and powerful hindquarters. If the length and obliquity of the 
shoulder, combined with high withers, assists the balance, by enabling the rider's weight to be erenly distributed, it is the relative length and vertical position of the arm, still more than the direction of the shoulder, which gives freedom in the paces and handiness. 'The power of the hindquarters, which drive the horse forwards or backwards, gives the horse control of himself and of his balanee; it gives him the free use of his hocks and enables him to bring them more or less under his body; it enables him to pull himself together, or to extend his paces according to circumstances; in fact it puts it in his power to take any direction or speed he wishes.

Morcover, if his confidence in his long and oblique shoulders enables the horse to land lightly over a fence without any apparent effort, it is the contraction and thrust from the hindquarters which gives the spring that carries him over. The riding horse should therefore have a large hip bone, projecting well at the side, and extending slightly abore the spine, producing what is called the jumping bump.

The perfect shape.-If one adds to the requirements just mentioned, a forchand formed less by a uscless length of neek than by the addition of cervical vertebræ, and a wither running well into the back, one will have the frame of a riding horse in all its uscful beauty, and in consequence, the type to look for.

One of the first qualities of a riding horse is, that he should carry his saddle in the proper place, that is to say, the girths should naturally pass well behind the elbows.

The other points to look for are-

A broad forehead and a well-sct-on head. 
An open, intelligent eye.

A well-proportioned and well-set-on neck.

A high wither, running well into the back, and slightly higher than the quarter's.

An oblique shoulder.

A long and straight arm.

A forearm with large powerful muscles.

$\Lambda$ deep chest.

A strong back.

A wide loin with strong muscles behind the saddle.

Well-shaped long quarters, slightly sloping and muscular.

Large prominent hips.

The muscles of the thighs and second thighs well developed and extending well down towards the hocks.

Short, compact body with well-sprung ribs.

Knees low down, large, wide, and flat.

Cannon bones short and strong.

The hocks large, straight, and low.

The legs hard and clean, ending in four good symmetrical feet.

A fine skin.

A horse with these characteristics will not only be well balanced, but will move well and possess a free striding walk; a trot starting from the shoulder, which is long, easy, and regular; a gallop which is smooth, powerful, and extended.

Quality.-This results from the constitution or power of endurance of the organs with regard to their work; blood, which by the energy it gives cnables the organism to resist the ordinary causes of collapse; stamina or cndurance in any kind of work.

Courage, however, alone secures the maximum 


\section{EDUCATION OF THE HORSE}

advantage of this quality. The horse's quality arises from various eauses; it depends upon good food from the earliest age, from the soil on which he has been reared containing lime, and so developing bone and strength of musele; but it depends ehiefly on the breeding of the horse. It is indispensable therefore to secure the proper mating of the thoroughbred horse with the half-bred mare to transmit the blood, and to maintain the size. 


\section{CHAPTER II}

\section{GENERALITIES}

TuE quality and docility of the horses are essential elements in the value of cavalry.

They can be obtained, or at any rate largely developed, by the care given to the education of the young horses.

\section{INFLUENCE AND RESPONSIBILITY OF THE} COMIMANDING OFFICER.-The Colonel helps, by all the means in his power, the regular and complete course of instruction, which must be considered as the basis of the value of the regiment as cavalry. By frequent inspections, by courtesy and encouragement accorded to offieers, non-eommissioned officers, and men, who distinguish themselves in the course of training, the C.O. exercises a personal influence. on the nature of the results obtained. He gives orders for the perfect upkeep of the riding schools, for the allotment of exercising grounds suited to the work, as also for the laying out of courses on which the horses can be galloped in all weathers, and in every way shows by the great trouble he takes himself, how keenly interested he is in the sueeess of the training, and consequently in the energy which others put into their work.

No horse is admitted into the ranks without having 
been submitted to the examination of the Colonel by the man who has trained it.

Influence and responsibility of the squadron leader. -In cach squadron, the squadron leader is responsible for the training. All the licutenants and secondlieutenants as well as the non-commissioned officers, and certain ehosen troopers, take part in the work.

The training lessons, which are given to the young horses by the N.C.O.'s and others, are direeted by an offieer specially seleeted for this service, and chosen by the squadron leader.

Qualities of the instructor and the trainers.-This instructing officer should be selected from among those who have already had a certain experience, and who possess special aptitudes for the work, of which the most important are sound eommon sense and a love of method, without which the most brilliant qualities remain sterile if not dangerous.

During the training the young horse is always ridden by the same man. There results from this association between the man and the horse, a mutual understanding, which in course of time serves as a point of departure in the education of the latter. The training of the horses is superior to any other duty in the squadron, and exempts the man from having to train recruits. Consequently the men so employed are withdrawn from other duties while the training lasts.

The men employed in breaking in the horses are chosen from amongst those who are fond of a horse, love grooming him, and are known to be patient and kind.

The non-commissioned officers and troopers selected for training horses should also possess an cducation 
and a proficiency as horsemen, without which there is no hope of success. In fact, if it is the well-trained horse that makes the good horseman, it is also equally true that the only man capable of training the horse is the man who is skilled in riding him.

Care on arrival at the regiment.-On arrival at the regiment the young horses should be placed by themselves, and entrusted for some days to the veterinary officer, who considers them from the point of view of health; but this isolation should be as short as possible. They are then handed over to the squadrons to which they are allotted, stabled together, and given a special treatment, intended to acclimatize them.

The first care should be to keep them healthy, to adapt them to military life, to develop their strength by well-regulated feeding and exercise, to get them accustomed to men, to being shod, groomed and saddled, and lastly, to the weight of a man on their backs.

The object of the education of a young horse.The training lessons are given either in company or alone, taking into consideration the horsemanship of the riders and their experience, the character of the horses, and certain considerations of service, of time and of place.

'The troopers' horses before they can be considered completely trained, should be able to execute all movements preseribed by the Cavalry School, and especially they should be perfectly quiet when being mounted, should walk freely and regularly in a straight line, should be handy in all the paces and in all changes of direction, and should pass or jump every kind of obstacle, endure the pressure in the ranks, and leave 
them readily; be used to all parts of their cquipment, not be frightened by sights or sounds, and should be trained to arms.

The various phases in the training should be left to the initiative of each instructor, but they ought all to be governed by two fundamental principles, viz. giving the horse confidence, and the methodical graduation of the demands of the rider, based on the association of sensations.

A horse may be giren confidence in an infinite number of ways of which the most usual are caresses, repose following immediately on the least sign of obedienee, the easing of the legs and reins, the passing to a walk after the faster paces, or even the getting off the horse after a result has been obtained.

One should never lose sight of the interest which comes from carrying on the training without haste, and methodically.

Nevertheless, kindness and patience are useless without firmness. The persistence in the employment of the aids; the energetic use of the legs or of the spur, the whip, or the cavesson, are means which can be used with some horses whose will has to be dominated.

The measure and the i propos with which one should combine these various means camnot be positively laid down; it is their just application that displays the tact of the trainer. The officer in charge of the training exercises, moreover, a constant and rigorous control as to the manner in which the riders make use of the different means at their disposal for overcoming the resistance of the horse.

Finally, the good condition of the horses, the hardness of their legs, and their good disposition, are the 
best criterion of the competency with which the work has been directed.

Divisions. Breaking in-Training.-The education of young horses lasts two years. This is a rule which admits of only one exception, and that is in the case of mobilisation.

The preparation of the army horse, for his definite cmployment, has two periods, each having its own distinct object.

1. The breaking in, to which is assigned the first year of military service of the young horse (four to five years old); it has for its object the physical development of his power, acquired by appropriate work, and the formation of his character.

2. The training proper, to which is given the second military year (five or six years old) and which has for its object the complete submission to the aids.

These two years, notwithstanding their special denomination, do not constitute two periods clearly defined; they represent, together, the time which is indispensable to make the remount fit to sustain the calls of military service. The very words "breaking in " and "training," convey in themselves, and constantly impress upon the instructors, the profound difference which exists between the work which a young horse not yet fully set can stand, and the demands that can be made on a six-year-old horsc.

In effect, the young horse should not be submitted to the difficult exercises of training, until his moral development, on the one side, and the development of his frame, on the other side, permit of his going through without fatigue.

The gradation to observe in the exercises, to which the horse is submitted for his derelopment, constitutes 
a definite training with laws, principles, and hygiene, which originate in the very nature of the horse.

With regard to the training, the progression is much the same as that employed in making the horseman. This methodical order proceeds from the simple to the complex, graduates the actions of the rider according to the degree of obedience the horse shows, and progressively varies the combination of the aids. It is necessary to be careful, at any rate at first, to execute the movements under the same conditions and in the same manner, until the horse is confirmed in the knowledge of the rider's actions by the effect of repetition. It is only little by little that an obedience, at first uncertain and difficult, will be transformed into a habit almost instinctive.

The second military year being finished, the young horse takes part in the work of the old horses in the training of the unit, and thus learns perfect obedience. It is a useful transition between the training proper and the time when the horses enter definitely on service.

Circumstances which influence the duration of the education of the young horse.-In the education of the young horse certain circumstances have to be considered, which will influence his training. His health, breed, age, feeding, previous work, character, natural balance, and his being unused to the saddle, are so many conditions which will hasten or delay the progression of the work. Some aged horses sent direct to the regiment by the remount depots can at once commence the advanced training, others, on the contrary, and in particular brood mares put back to work, should be kept at the carly breaking work until their strength is sufficiently developed. 
The instructor should study and weigh all these considerations, and he will draw upon his experience for means which will help him to attain his end, i.e. to bring all the young horses to seven years old, healthy, free from blemish, and capable of fulfilling on all kinds of ground the duties which a soldier has to perform on active service.

The instructor ought always to keep the following rules in mind :-

Never commence work without having clearly fixed in his own mind the end to be attained. Proceed in the education of the horse from the known to the unknown, from the simple to the complex.

Employ exactly the same aid effects of placing and stimulating to obtain the same result.

Remember that in the execution of all movements position should precede action.

Never demand anything of a horse which still vibrates under the impression of a previous demand.

Never fight two resistances at the same time.

Never confound the want of aptitude in the rider with the ignorance or bad disposition of the horse.

Demand a new movement at the end of work; pat the horse and get off him.

In addition to these rules it is right to remember that all through the course of the education of the young horse "one should be content with a little progress every day, to demand it, but nothing more." "The rider should have clear in his mind the point at which the horse has arrived on the previous day, and not aim at the immediate and perfect execution of the movement" (General l'Hotte). 


\section{CIIAP'TER III}

"BREAKING"

TIIE OBJECT OF BREAKING

1. 'To encourage by good stable management, food, and work the thorough development of the physical power of the young horse.

2. To give him the first instruction in the aids, and to prepare him for their discipline.

It has therefore for its principal object, as has already been stated, the gradual eonditioning of the young horse. The progressive handling, the time spent in the special stables, where the young horse is fed with corn and given a eertain amount of exereise, serve as a commenecment of this training and help the early efforts.

Certain demands, military or physical, nceessitate the division of the breaking into several phases, each of which has an object imposed by these obligations.

PHASES. - The dates which fix the period of these stages are-

1. The beginning of January, when the early training ought to be accomplished.

2. The first days of March, when the mobilization training commences.

3. The departure lor the manœuvres, which marks 
the end of the breaking and allows of an almost complete rest.

The time when the coat changes, and that when the horses are turned out to grass, complete the series of phases, which in the same way will again be found in the second year.

The importance of work.-Work is the most important factor in breaking. Besides the part it plays in the development of the organs of the young horse, it is the regulator destined to keep his health and character in proper poise.

If the young horse does not get sufficient work he becomes too fat, and at the same time too lively; he damages himself under his own weight, increased by that of the rider, and he ruins his mouth by fighting against the hand that tries to bring him to order. Nevertheless, like all army horses, it is necessary that the young horse should be in somewhat high condition.

The work he is given to do out of doors, should be long and slow, one hour and a half at least; of short duration in the school, say half an hour.

The employment of felt boots or bandages is recommended to preserve the legs, and especially while the horse is being lunged.

Dismounted work. Walking out on the rein.Leading the young horse by the side of old stagers is, during the first days, an excellent exereise, which allows of the horse getting rid of his superfluous energy without danger to his legs, of his getting used to strange objects, and of his finding the calm which is indispensable in useful work. The many cireumstanees in which the eavalry horse has to be led in hand makes this exereise very profitable, but it is not necessary to continue it for any length of time. 
During this excreise, it is advisable to lead the young horse first in one hand, and then in the other, so as to avoid always bending him to the same side.

The results to aim at during the first phase, are obedience on the lunging rein, and standing still whilst being mounted; in fact, to teach the horse to adjust himself under the rider, that is to say, to walk steadily forward in the new balance. This triple aim is of the very greatest importance for the future, and will not allow of half measures. The instructor must therefore give all his attention to the perfect execution of these lessons.

Work on the lunging-rein.-This is of the greatest use in the training. It familiarizes the horse with the man, whilst at the same time making him feel the power of his master, and indicating to him the first ideas of obedience.

The lunging-rein, moreover, enables one to make him work at the fast paces without fatigue, to get rid of his superfluous energy when he cannot be ridden, or when his rider is absent, and to dominate by hard work a vicious horse without fear of damaging his legs. The work on the lunging-rein is also the basis of training a horse to jump. One should, moveover, profit from the authority which it gives to the man over the horse to get the latter used to being girthed, to carrying the sword, to standing still at the mounting block (in the case of difficult horses), and finally to teach him to yield the quarters with the whip.

All horses ought to be perfectly trained to the lunging-rein.

The eavesson which is used for this work should be sufficiently large, well padded, arranged so that the mountings eamnot hurt the eye on the outside in the 
work on a circle, placed sufficiently high so as not to interfere with the breathing, and it should not have too much play, so that the action on the nose should not be too strong.

The whip is carried in the right hand if the horse is working to the left, and with the point behind. It should be hidden as much as possible from the horse, and should only be used to indicate one's wishes or to touch the horse; it should never have a lash.

The first lessons are of such importance that they should be given to each horse by the instructor himself, or by specially qualified N.C.O.'s with experience in the art. Moreover, if these lessons are well given, a few short lessons will suffice.

The instructor holds the lunging-rein in the right hand, about two feet from the horse's head; the end of the rein being looped up and held in the left hand.

After gaining the horse's confidence by patting him, the instructor makes him move forward, by stretching the rein slightly and giving a click of the tongue. He walks thus alongside the horse in the riding school in a straight line or in circles. He stops frequently saying, "way" or "wo," pats the horse whilst standing still; lastly, he changes the hands holding the rein, and repeats the lesson.

If the horse moves forward at the elick of the tongue, stops at command, and walks on kindly without pulling, the instructor ceases to work on a straight line, lets the rein slip slightly through the hand, and starts the horse on a small cirele, making use of the long whip, or cutting-whip; he himself walks round with the horse, a little behind the shoulder, so as to maintain the forward movement. He stops the horse often, goes up to him, pats lim, and then restarts him. IIe 
proceeds in the same way in a circle to the other hand. If the horse hesitates to move forward, the instructor mores backwards towards the quarters, yiclding the rein at the same time. If necessary, he can get the assistance of another man. 'The important point is not to be rough with the horse, nor by frightening him to make him pull backwards. When the horse works well to both hands, calm and at the walk on a small circle, the rest of the training is a simple matter.

The instructor makes him first trot, then canter; to increase the pace he uses his roiec or the indications of the long whip; he at first always follows the horse on the circle, walking behind him on a level with the quarters; moving on the contrary towards the shoulders, if he wishes to stop; it is only little by little that he decreases the circles, and he himself follows till he becomes nearly stationary.

The length of the radius depends upon the speed. The cadenced trot on a small circle is an excellent exercise for the young horse; on the other hand, at an extended trot, or at the canter, there would be danger in restricting to a small circle animals whose joints are essentially weak.

If the horse rushes off suddenly, it is necessary first to yield the rein freely, then to oppose the morement and bring the horse back little by little.

If the horse stops, one can make use of the long whip to force him to move forward, directing it towards the quarters. If the horse comes in closer, he should be sent out again by directing the long whip towards his shoulders.

If the horse pulls violently at the rein when working at the fast paces, it is a proof that sufficient time has not been taken in the training. He should be stopped 
frequently, and recommence the work at the cadeneed trot on a small circle.

It helps in the early lessons to work in one of the corners of the riding school.

The wall ean also help in stopping a horse who has got out of hand.

The voice, used at first with power in order to make the horse understand, should secure the same obedience when the indications are more quietly given.

The lunging-rein equally communicates to the horse the instructor's will; light horizontal oseillations send the horse away from the centre; jerks, more or less sharp, regulate his paces or stop him, when he does not obey the voice.

If the work on the lunge has been well directed, the horse should be calm and regular in his movements on the circle; pass freely from one pace to another at the simple indication of the voice; come in or go out from the centre, according to the liberty given him; in a word, he should be on the hand when the lungingrein is slightly stretched, as later on he should be when the reins are stretched.

Getting him used to the saddle.-When the horse has been settled down to work, and is perfectly quict in the cavesson, he should be gradually accustomed to the girth, as this lesson is apt to cause considerable trouble when it is given in the stable.

The saddle is first put on without stirrup leathers, the girth is at first loose, and it should be gradually tightened up during the work. When the horse is used to the saddle and girth, the stirrup irons are added, and are allowed to hang on both sides, whilst the horse walks and trots. IIe is thus prepared for the mounting lesson, which becomes easy; resistances 
are generally the result of saddling and mounting a young horse for the first time on the same day.

The mounting lesson.- The instructor, in accordance with eireumstanees, decides on the most opportune moment for giving the mounting lesson, but he should always give it after work, because the consequent fatigue is a guarantec of calm. This lesson can also, in eertain eases, be given during the lunging lesson, but always when the horse is relaxed by exereise. The instruetor personally direets the first lesson, which is giren to each horse individually, and he will exercise the greatest gentleness and patienee.

Accompanied by an assistant, carrying if desirable a sieve full of oats, he places himself in front of the horse and pats him, without taking hold of the reins, exeept in case of necessity. The rider gocs up to the horse's head, strokes him on the face, the eyes, the neek, and the quarters; strikes the saddle, moves the stirrups about; then he takes the reins, at a good length, and mounts the horse without haste, but also without hesitation. If during the lesson the horse moves or goes backwards, the trainer goes back to the horse's head, draws the horse forward with the bridoon rein, and again mounts quietly. The rider takes care when placing the foot in the stirrup to drop the toe so as not to irritate the horse by touching the side. After raising himself in the stirrup, he should immediately place himself in the saddle; as, by placing the whole weight of his body for any length of time on the one side, he disturbs the balance of the horse, and makes it impossible for him to stand still. He will place the right iron on the foot with the right hand; if he searches for it with his toe he will probably frighten the horse. 
He should generally avoid starting the horse into the walk immediately he is in the saddle, so as not to associate the action of mounting with forward movement in the animal's brain. It is even useful at first to finish work with the mounting lesson, and then return the horse to the stable as a reward.

If any of the horses give serious difficulty they should immediately be replaced on the cavesson.

The mounting lesson should be given on both sides, and be repeated every day. 'This part of the education of the young horse should be thorough. It is necessary to obtain absolute docility in the midst of noise and movement, in fact in all circumstances in which it would be essential in war to have a horse absolutely stationary when being mounted.

Nevertheless, one should not, at first, be too exacting.

Training to the sword.-The lunge can be used for getting the horse accustomed to the sword. As in the case of all new experiences, it is as well to wait till work is over before giving this lesson. At first the scabbard only should be placed on the saddle, and when the horse ceases to fear it, the sword can be added. This work, which is done at the three paces, is, it should be understood, varied with earesses and frequent periods of repose. It is no more than a prelude to the series of exercises, intended to accustom the horse to the sword, which are practised when working in the open.

Mounted work out of doors and in the school.As soon as the horse is accustomed to a rider, commence to get him into condition. This work continues without interruption till the end of the military ycar, that is to say, till the manœuvres, and it should be given as much as possible out of doors. 


\section{THE OBJECT OF BREAKING}

It is evidently in the open, and in working on straight lines, that the young horse acquires most rapidly the fullness of his power. Nerertheless, the early excreise is giren in the school, so that the instructor can give a more personal supervision and be able to study more carefully the horses and the men, and to avoid accidents which are always possible. Some old well-broken horses introdueed amongst the young ones, will have a good influcnec. The work is also carricd on in the sehool during eold weather, and the opportunity will be taken for giving the first lesson in the aids.

Early education in the aids.-This carly education is indispensable before a horse can be ridden out of doors. It consists in teaching him to go forward to the pressure of the legs, to reduce his pace and stop when the reins are felt, and to turn when simple indications are given.

The horses are bitted with a double snaffle or with a bridoon only. The quality, upkeep, and plaeing of the bits is an object of special and constant attention.

The walk.-The basis of all training is a free, vigorous, forward movement, and it is neecssary from the very first to train the horse to yield to the pressure of the legs. This is the first lesson to gire, and it should be constantly repeated. It demands at first the following precautions:-

1. Never allow the legs to remain fixed against the sides, but apply them by frequent intermittent touehes.

2. Close in the legs near the girths, and do not animate the horse by applying them too far back on the flanks.

3. Commence by giving this lesson when changing from the walk to the trot, afterwards when extending 
the trot, and later on in passing from a stationary position to the trot.

4. Assist the action of the legs by aecompanying it, if necessary, with a click of the tongue, or with touches of the whip on the shoulder. This last recommendation is especially relevant to the forward movement when the lesson is given in the school; when out of doors, especially when walking behind an instructor, the young horse has a natural tendency to go forward in following him, and this is another reason in favour of commencing outdoor work as early as possible.

In the forward movement the reins should be stretched. If this is not the case, the horse, instead of being collected, wobbles about, and the rider has no power to direct him.

It is easy to keep the reins stretched in the case of fairly energetic horses with a natural desire to go forward; the rider has merely to fix the hands, and without checking the horse's pace, to moderate little by little his keenness. It is more difficult to teach the habit of feeling the hand to young horses just up from grass, underbred, and without vigour. These as a rule only stretch the reins to get their heads carried when they are tired. With this kind of horse, it is at first the rider who must search for the horse's mouth. Later on, when work has strengthened the horse, it will be he, who, having formed the habit of feeling the bit, will, when solicited by the pressure of the legs, search in his turn to streteh the reins. If he obeys the pressure of the legs, or merely a touch of the heels, the work on a straight line at the walk, trot, or gallop, will bring him insensibly to take the desired feeling on the hand; it is then for the rider not to discourage him by inappropriate severity; a fixed hand with 
contracted fingers would spoil the horse's mouth and have a bad result.

Consequently, in this first lesson of the action of the legs, the hand ought not to oppose the extcnsion of the neck; on the contrary, the fingers should be half open, so that the neck can readily strctch itsclf, and that nothing should run counter to the goodwill of the horse in his forward morement-to sum up, the legs are active, the hands passive.

There may be an advantage in putting on spurs carly in the breaking of ecrtain horses especially lacking in vigour, and which are irresponsive to the pressure of the legs; but even in this case the spur should not have sharp rowels. With well-bred horses it is usual not to wear spurs at first. The use of the spur, in most cases, does not seem to give any special lesson : the horse nearly always replies to it by rearing.

In the case of mares or of horses which cow-kick and refuse to go forward, it gencrally suffices to put them back to the eavesson, and to give them a stroke of the whip at the moment the rider applies the spur.

The halt.-To stop the horse, the rider gradually increases the pressure of the fingers on the reins, while at the same time straightening his body. He regulates the vigour of his action in accordanec with the sensibility of the horse's mouth.

When stopping, the horse should remain wellbalanced and light in hand.

One should not stop nervous horses too often, or those which are balanced too much on their hind quarters, or those which have a general tendency to get bchind the hand; on the contrary, stop those often which, owing to their conformation, have too much weight on their shoulders. 'Training is nothing clsc 
but the search for balance; halting is an excellent exereise for horses high and strong in the hind quarters, and which are consequently difficult to regulate in their paces.

Turning.-Horses are accustomed to follow the man who leads them with the bridoon reins : it is this open action of the reins, always responded to by the horse, which serves as a basis for guiding him.

(a) To turn to the right the rider opens slightly the right rein by earrying the hand forward and to the right; it is necessary in this movement to carry the passive hand forward and down, so as not to counteract the active rein.

It is in fact very important with young horses, that every sensation that we give him should be perfectly distinct and clear.

The effect of opening the rein should make itself felt to the side, and with the least possible backward tension. It nevertheless provokes a slight reduction of speed which the pressure of the legs should counteract.

(b) The horse having been taught that his main duty in life is to go forward, as the action of a single leg, whilst it stimulates him to move forward, pushes the quarters to the opposite side, one takes adrantage of the fact that the action of the hand tends to the same result, to associate with it the action of the leg, and thus strengthen it. Thus the young horse is taught the action which results from the opening of a rein, and the pressure of one leg, and accustoms him to carry the quarters to the side opposite to the active leg.

(c) When the horse readily obeys, at the walk and trot, the action of the opened rein, teach him the action of the indirect rein, that is to say, in ricew of the 
exercise to which he will have to submit later on, when being ridden with one hand, teach him to turn, say to the right, with the left rein. It is suffieient, to obtain this result, to make use of the corners of the sehool, and make the horse do some circular morement by opening the rein; and the moment the horse commences to obey, we should substitute the action of the indirect rein by carrying the left hand forward and to the right; the opened rein acts as an interpreter to the indirect rein, and the moment this latter comes into play we should ecase the action of the opened rein and drop the right hand, so as to allow the indirect rein to have its full effect. After sereral suceessive and alternative indications of these two actions, the rider diminishes and then suppresses the employment of the opened rein, in proportion as the horse better understands what is wanterl of him.

The rein-back.-This is a very secondary movement in breaking. It should only be executed when on foot, and only a few steps at a time.

It is to these elementary notions of the airs that the first lessons confine themsclves, before taking the horse out into the open. Every possible movement at all the paces eomes from four elementary actions, which it is necessary to make him understand, immediately and separately, before associating them so as to produce combined effects. These actions are, to move forward to the pressure of the legs; to slow down, or stop, on the reins being stretehed; to more the shoulders and the quarters to the side. These elements being well understood by the horse, the ordinary riding excreises, judiciously arranged according to his powers, development, and health, finish his edueation. This will be the work of the final training. 
First lessons in the eanter.-If special courses of grass or sand are not arailable, in the case of young horses, work at the canter should be given in the school. In the case of horses from the south, which eanter naturally, the simple pressure of the legs ordinarily suffices to bring about the disturbanee of balance which determines the pace desired. It is not the same with horses from the north-west, often underbred or descended from the trotting strains. The start of the canter by extending the trot is difficult, and ought to be severely discouraged as a cause of disorder and of accident. It is, on the contrary, by starting, from the slow trot on the circle, or when turning the corners of the school, that the horse is got to break into a canter on the desired leg. In every case the aids to use are the action of the outside rein drawn behind and across the withers-diagonal effect-and the pressure of both legs. These aids, by restraining the action of the outside shoulder, push the horse to the other side, disturb the balance towards the side of movement, and force the horse to strike off at a canter. A few clicks of the tongue help the first starts.

The riders in adapting themselves to the rhythm of the canter, by continuing the action of the legs, and by accompanying the morement of the neck with the hands, help the maintenance of the pace. After a few lessons the starts become more and more calm, but one should not ask a young horse to make too many of them. It is periods of cantering, and not starting the canter, which are of importanec. Out of doors, as in the school, the instructor only gires this lesson to a few horses at a time; he regulates the number and length of the canters in accordanee with the temperament, character, and brecding of the horses. Those which 
do not gallop go out for walking excrcise alone, or are given the mounting lesson.

Conditioning.-Work in the open air ought to commence as soon as the young horses, aceustomed to the rider's weight, have sufficient knowledge of the aids to enable them to be taken out without fear of accidents.

'The open air, the employment of the paees in aceordance with the nature of the ground, their regularity, graduation in length and speed, the periods of rest and slackness intelligently used, are the elements which the instructor has at his disposal to attain his object, and to develop normally the organs of the young horse.

Organization of the lessons. The leading horse.The instructor divides the young horses into groups aceording to their breed, character, temperament, and paces. The examination which he has made during the early lessons in the school, the study of the registers, in which are entered by the Remount Service the performanees, and the age at which the horse was bought, help to fix their first division.

Every day, as the horses leave the stable, the instructor cxamines the legs of the young horses; he then has them walked round him, notices their apparent condition, and their expression of face; asks the riders about the appetite and character of their mounts, about the difficulties which oceur, and as to the results attained. The instructor groups, in accordance with the information received, the horses capable of doing the same work, and marks off those which ought to be sent out alone.

The horses which work together are divided into parties of four or five, and do their work on different 
routes, or at least sufficiently separated to insure their independence, and freedom from disturbance. At the head of each group, at any rate during the first few days, an old horse is placed to serve as instructor.

The value of the different paces.-The walk plays an important part in conditioning, because it can be maintained for a long time without fatigue; it supples all the joints when it aequires its full extension; strengthens and hardens the tendons, and also produces calmness and strength. By gently following with the hands the movement of the neek, which is very pronounced in the extended walk, the rider at the same time gires confidence to the horse, and accustoms himself to maintain eontact with the bit. For all these reasons this pace plays a very large part in the breaking.

The trot is useful at the outset, firstly to settle the horse down, then to get impulsion and bring him to accept the support of the hand, which is indispensable in maintaining movement on a straight line. Thus held between the legs which push, and the hand which supports, the horse gets into the habit of stretehing and fixing his neck in the direction of morement, which assists his future training.

From a physical point of view, the trot quickens the circulation, whilst at the same time it derelops the museular system. For the young horses, as in the case of the young horseman, the periods of trotting are at first frequent and short. The duration of the trot is inereased when through work the horse commenees to get into condition.

The canter is the very best exereise for the young horse, it places him at the same time on his hind legs and on the hand, and develops the lungs to the greatest 


\section{THE OBJECT OF BREAKING}

cxtent. It is a pace which the horse ought to be able to keep up for a long time without fatigue, and he should be taught it early in his training, but on account of the mechanism and the power of this pace, one should only demand it, out of doors, on very good going. If good going is not available, it is preferable, until the horse is more advaneed in condition, to canter him only in the school.

Out of doors there is no question of carefully prepared starts in the canter; the instructor procecds out of doors, as in the school, by upsetting the balance, and regulates the duration of the periods of cantering according to the progress of the horse's work, and his state of condition. At first avoid, under pretext of regulating the paces, entering into a confliet which is harmful to the mouth of the young horse, and likcly to break his paces, or destroy his natural impulsion. During the whole of this part of the work, the principal aim of which is physical derelopment and the giving of confidence, the rider plays to some extent a passive rôle, and makes erery concession which will not have a bad effect on the health or character of the horse.

Opposition of the young horse.-When dealing with these a very great difference should be made between the manifestations of stubbornness or bad temper, and bounds which result from lightheartedness.

If it is indispensable to make a point of defeating the first named, from the commencement, it is equally a mistake to punish a young horse for shying. When the rider feels the horse ready for a fling, he should close in his thighs and legs, drop his hands, close the fingers on the reins and wait.

In the same way when the young horse gets out of hand, rushes forward, or throws himself to one side, 
one should not try to restore order, as most inexperienced riders do, by a regular action of the aids (since the young horse hardly understands them when he is ealm and in a slow pace); one should fix the hands, and then as soon as the horse is calm, stop him, replace him, and press him forward. This method of procedure is, moreover, always, even in the case of old horses, the one which gives the most certain and prompt results. In every case the instructor recommends patience and kindness. He moreorer instils into himself the teaching of the most famous masters of the French school, who had for maxim "to aroid upsetting the young horse, and not to destroy his gentleness, because it is with the horse as with fruit, what is once taken away never returns" (Pluvinel Le Manège Royal).

Preparation of the young horse for his eventual employment in case of mobilization.-After a few weeks' work, it is indispensable to commence to prepare the horses for the part they will eventually be called upon to play in case of mobilization. Whilst rigorously following the progression established with a view to the exercise of the horse, one can, for example by taking the sword and the bridle when working out of doors, habituate the young horses from time to time to the equipment, to the distinctive headdress of the rider, to the cuirass, to sword exercises when standing still, walking, or on the mareh, and ean also get them used to firing, by being present at rifle practice.

The bridle.-As soon as the horses have free and extended paces, and they accept without hesitation the support of the hand, one can, without inconvenience, put a double bridle on them, on condition 
that only work on straight lines is demanded, until the bars of the mouth are used to the bit; by doing this one also aroids letting the young horses form the bad habit of carrying their weight on the shoulders, and bearing on the bit. One should also take off the curb chains, and choose mild bits.

There is not in training any regulation method of holding the reins. It is for the rider, in accordance with the end he has in riew, and the resistance he cncounters, to find the method which makes the most effective use of the actions of the bit and of the bridoon. But the best method of holding the reins is that which makes it most easy, when occasion demands, to separate the reins and hold them in each hand.

Individual work.-The individual work of the horses, which it has not been possible to commence in the school or on the parade ground, is carried out with great regularity out of doors. The instructor takes advantage at first of the return journey to divide the young horses into groups, reduced daily in number, and sends them by different roads. These groups in their turn subdivide themselres into smaller and smaller groups, and the young horse is thus progressively brought to work alone. The demands are increased until one has obtained from each horse a ready obedience and an absolute calmness.

The mounting lesson is frequently given during the whole time that work is earried out in the open. The results obtained in the school have only ralue, in so far as they serve as a basis for the employment of the horse in the country.

Early jumping lessons.-There is an adrantage, in commencing the jumping education of the horse 
at an early age, providing one does not aim at more than making the horse clever and free. Do not impose on the horse any excessive effort, and whilst he should be made to respect the obstacle, it is best to teach him over low but fixed jumps.

Training in hand.-The horses having becn accustomed by work on the long rein to follow their riders without hesitation, we make use of it to get them to jump in hand all the small natural obstacles which one meets, such as ditehes by the side of the roads and small streams, and to descend steep slopes. The instructor should not forget that his objeet is to derelop the clererness of the young horse, that this is only secured by calmness, and that calmness is the result of the trainer's patience. No violent methods are, therefore, employed in this work. There is need, nevertheless, to take the greatest precautions, that the horse does not make use of the liberty, which is of necessity given him, to turn on the man and strike him.

Jumping obstacles by the horses led in hand should not be considered mercly as a means of arriving at jumping when mounted, but also as an end in itsclf. It is a method of getting orer obstacles which should be taught and made perfect. It is on this method that a body of cavalry, as well as a single soldier, must depend, when faced with a difficult piece of ground.

Jumping on the lunging-rein.-As the horses become stronger the instructor adds to these lessons, in the case of each individual horse, some jumping lessons on the lunge or at liberty. These excreises increase the clererness, develop the powers, improve the balanee, and consequently inercase the confidence of the young horse. 
For jumping on the lunging rein the horse is put on a circle, or, to be more exact, on an ellipse, so as to have some distanee of a straight run at the jump, which cuables him to regulate his stride and aroids the necessity of turning sharp after jumping. The instructor, to keep him on this cllipse, must follow the horse to some extent. IIe should always be in a line with the horse's quarters when he arrires at the jump. When the horse takes off, and cluring a few strides from the jump, he lets the lunging-rein out. He commenees with a bar on the ground, and this should not be raised till the horse passes over it at the three paces without lengthening his stride or slowing down.

'To calm the horses and teach them to raise the points of their shoulder, they should be frequently made to jump from the walk and trot, and one should replace the bar on the ground whenever the horse shows fear or nerrousness. Often vary the nature and the height of the jumps, and train the horse to jump equally well to either hand. Never try to reach the limit of the horse's power; it is by work, patienee, and plenty of small jumps, that his powers are developed, and he becomes a reliable fencer. The instruetor should consider the jumping lessons as diffieult work, and so give them himself and get the assistanee of the N.C.O.'s and capable troopers.

Jumping at liberty.- Jumping at liberty, in the cireular enclosure or in the riding school, ean be usefully employed to perfect the style of eertain horses, and to give freedom to those which lack this quality. But it is very delieate work, which requires the presenee and vigilance of the officer.

'The work in the circular cinclosure makes the 
horses calmer than work in a square enclosure, as they can be allowed to take several consecutive turns.

The enclosure should be made on a piece of ground measuring 45 by 25 yards. It is composed of two tracks placed side by side, each one formed of two straight parts joined by a suitably rounded turn. Each track measures from 3 to 4 yards in width. The three palings which separate the tracks are, for instance, the interior one about 5 feet high, and the exterior one 6 feet high. On the straight portions are arranged jumps of various kinds, so made that they can be negotiated both ways. The inner track, reserved especially for teaching high jumping, only contains obstacles which ean be raised or lowered according to the capability of the horse. The outer track, intended to make the horses clever across country, has fixed jumps rather more formidable than those the rider is called on to jump when riding over a country, banks of various sizes, ditches, and water jumps, etc.

The instructor stands in the centre of the enclosure and directs the horse's work with the voice and whip ( $c f$. "Dressage en libertś du cheral d'obstacles," by Comte Louis d'Havrencourt).

Jumping mounted.-When the horses jump cleverly and without hesitation, they should be mounted and jumped over some small obstacles, preceded by a clever old horse, the riders taking care to give the horses the free use of their necks, holding on by the pommel of the saddle if necessary.

Stable management. - The care of the young horses' health should be a subject of continual thought on the part of the officer in charge. 
Grooming plays a very important part in maintaining the horse in good health. Stimulate, by erery possible means, the emulation of the trooper's, to secure the perfect execution of this work. The squadron leader and the officer in charge of the training should visit the young horses every day in the stable, regulate the time of fecding, inquire as to the horse's appetite, examine the teeth, sec that the horses get their full rations, order suitable substitutes for eorn aceording to the season, fix the days and the time for mashes and give orders as to what they should be made of, and, finally, see that the horses have plenty of bedding, which alone will gire the rest indispensable to their health.

Weekly examination.-Once a week the oflicer's will have all the horses led out, without clothing, by the men who ride them, in order to form a better opinion of their appearance, and of the condition of their legs, examining carcfully the fect and shoes. This weekly examination gives much assistance in the future work.

Change of coat and green food.-The change of coat in March or April, and the diet of green food in May and June, give rise to depression in young horses. The casing down of work is at this time absolutely necessary, as also the extra feeding destined to overcome this physical depression, the effects of which are often felt for somc considerable time.

Choice of ground.-The choice of ground plays an important part in the working of young horses. Without exaggerating the precautions that should be taken, there is an advantage in choosing, at any rate for the gallop, ground as soft as possible. On hard ground the joints get tired and the tendons 
suffer. Heavy slippery ground also has its ineonvenience, the joints have extra work thrown on them, and windgalls and bogspavins make their appearance. When the young horse has obtained experience of outdoor work, has been strengthened throughout, and balances himself in his paces, it is cxeellent to exercise him over a rough and varied country, so as to arouse his initiative; one should give him great liberty of neck, and he soon will learn to get himself out of difficulties without help. 


\section{CHAPTER IV}

TRAINING

GENERALITIES. - The trained horse understands the intentions of his rider from the least movement, and replies to it at once rightly, lightly, and with energy. He is, in fact, a horse responsive to the leg, and light to the hand.

"Training" is different from "breaking" in that during the fifth year the aeclimatization and the physical derelopment of the young horse is the first consideration of the rider, who will make the greatest concessions because of his age, whilst at six years old, it is the horse who must yield to the demands of the rider and show a complete obedience.

The training should not be undertaken until the horse, strengthened by the open air, and a rational breaking based on the prineiple of continual impulsion, and confident in his rider, is in a condition to understand the language of the aids, and to yield to their demands.

To give good results, training should be based on a system, follow a method, and conform rigorously to the rules which spring from the one and the other.

The system is a collection of prineiples established by experience and justified by reason. In the case of 
training, the fundamental principle is to make a horse calm, impulsive, straight, and handy.

The method unites to the principles the way of carrying them out, and regulates the order of their employment. It varies according to the particular ends which one has in view and according to circumstances, time, and surroundings.

The method of training here explained aims at- :

1. The development and direction of the physical forees and moral qualities of the horse.

2. The obedience to the aids obtained by a rational and progressive education carried out without recourse to force.

3. The search for balance.

The means employed depend upon the temperament of the instructor, the ability of the rider, and on circumstances. An order of procedure, which lays down neither precepts nor methods, has no interest beyond its assistance to the memory, and the series of movements enumerated is merely the naming of the figures to be traced by the horse.

Now, in training, the figures have only value according to the way they are carried out. It is the position given to the horse's body by the aids of the rider which is of any value. One rider ean trace with his horse, in the best established order, all the figures laid down in the regulations, without obtaining the least result. Another, whilst working in the same figures, but with a clear end in view, for which he employs the aids, will train his horse very quickly.

The principal factors in training. The instructor.The value of the instructor and that of the rider plays a very important part in training. The instructor should possess a thorough knowledge of the horse, of 
the science of horsemanship both theoretical and practical, and the lore of mcthod; and in addition, if his advice is not sufficient, he should be able to show practically what he wants done.

The rider.--It is the personal value of the rider which is the principal factor in the training of the horse. No matter the method, the quality of the horse, the value of the instructor, if the rider does not know his work as trainer, the horse will never be obedicnt, or at any rate he will only be imperfectly obedient. In fact, to train a horse, the first and perhaps only condition is to be a fine horseman.

The work.-Every method of training which docs not commenee with the conditioning of the horse, is not suitable for military purposes. In training, as in breaking, outdoor work therefore continues to be the essential part. It is for the instructor to regulate the proportion to establish between the work in the open and the work in the school, in order to best carry out the exereise and training of the young horse.

Under normal conditions only one-third of the work should be done in the school. In any case, the work in the school should not last more than threcquarters of an hour, and there should be frequent periods of rest.

The duration of training.--One must not lose sight of the fact that the moral and physical derelopment of the horse, no matter how skilled the rider may be, is subject to the essentially variable laws of nature. No effort will hurry the natural evolution of the young horse, and take the place of the work of time.

Patience, and the normal gradation of the efforts, will make a considerable differenee in the training; to go slowly is to move quickly. 
There is, moreover, in the mind of the horse a sort of daily process of incubation, which we cannot perceive, and in consequence of which we see suddenly appear the position or movement we were trying to get, and which, but the day before, we despaired of obtaining.

The psychology of training-Influence of character and conformation.-The mental constitution of the horse has also a considerable influence on his education. It is, therefore, necessary to study it and turn it to account.

Its characteristic is the memory. This quality assists the training when one knows how to turn it to account. On the other hand, it makes mistakes dangerous; nothing is more difficult than to retrain a horse, that is to say, to make him forget his wrong lessons.

Aptitudes vary in animals, as also the degree of intelligence. Some understand at once what is required of them, thoroughbred horses especially, whilst others are very dull witted.

The horse is as a rule kind; he understands kind treatment, the tone of voice, and caresses. Blows do not bring him to reason, they only make him irritable and timid.

He is capable of attention and of reflexion, because he often executes better next day movements which the day before he attempted with difficulty. He has a strong inclination to imitate, and it is on this aptitude that the utility of the leading horse is based.

He is patient, but his patience is limited, and one of the greatest difficulties is to understand the limit to place on one's demands during each period of training. Notwithstanding the slight development of 
his intelligenee-nevertheless of a higher level than one thinks-the horse is eapable of ingenious ruses, he knows how to test his rider, and to find out the defenees which frighten him and make him yicld. Training diseiplines the horse, supples his will, but is not able to definitely ehange his character. A wicked or sulky horse, however well trained he may be, is always to be mistrusted.

By studying the mental faculties of the horse, and by assoeiating them with the horse's own efforts, the rider hastens his submission.

His physical constitution and his temperament also require careful attention. It is by reason of the length and direction of his various bones, of the more or less openness of the articular angles, of the easiness of nutrition and digestion, ete., that one is able to form an opinion of the resourees of the horse, and the difficultics he is likely to offer.

Nature of the training. - The instructor should draw conclusions from the examination of each horse as to the course of training which will suit him best, and regulate the work aceordingly. It is not possible to bring all horses to the same degree of perfection, but one ean always develop their powers, without at the same time trying to obtain by sererity that which they have not the strength to give.

The same principles direct the training, whether it is undertaken by the officer, or entrusted to a trooper. The difference only shows itself in the choice and variety of the means employed, and in the perfection, more or less marked, of the results obtained.

Certain methods of training claim to secure the absolute domination of the horse, and suceed in 
eftect, in completely mastering, under all circumstances, his intellectual and physical power. But these methods, which are based on the complete collection between the bit and the spurs, do not form part of secondary equitation. The demands of work in the ranks on all sorts of grounds, appeal on the contrary to the natural powers of the horse, to his instinct, often even to his initiative.

It is, nevertheless, indispensable, that in the execution of such simple movements as the walk, the halt, and the turn, the indications of the aids should not only arouse in the horse a superficial sensation, but that they should, as it were, penetrate to the very bones, and bring about an immediate and absolute obedience.

The basis of the equestrian language.-In order that the rider may transmit his wishes to the horse, act on his intelligence, and become his master, it is necessary to establish between them a sort of conventional language, which the rider can easily learn and make use of, and which the horse can easily understand and accept.

This language rests on the law of associations of sensations which is as follows :-

"When impressions have been produced simultaneously, or have followed one another immediately, it is sufficient that one be presented to the mind, for the others to follow" (Dr. G. Le Bon).

For cxample, if the horse goes forward to a click of the tongue, it is because on some occasions he has seen a long whip, has felt the whip, and heard at the same time the elick of the tongue. This last perecption, which reaches the ears, has but to manifest itself alone, and the sensations of the sight and the touch of the whip 
will present themselves immediately to his mind, and the horse will go forward just as he had done when he felt the whip. In the same way when the horse has learnt to yicld his quarters to the whip, he will later on yield them readily to the pressure of one leg, because the two sensations will have been associated from the first.

The movements which the horse naturally executes, under the action of the aids are fer. The quictest horse is, therefore, unable to carry out the instructions of his rider if he does not understand them. It is by depending on the prineiple quoted above, that one forms the language which will make it possible to establish this indispensable co-operation. Sight, hearing, touch, and cren taste, come successively into play, and have each their part in this education.

It is on the lunging rein that the first elements are taught. The touch, and then the mere sight of the whip, produces the forward movement, to which will be associated the elick of the tongue, and for which will be substituted later on the pressure of the legs.

The pull on the lunging rein in the same way prepares the lesson of the opened rein, which in its turn will serve to explain the action of the indirect rein.

The actions of opening the rein, and the indirect actions, will eventually bring the horse to understand the actions of opposition, on which will soon be grafted the lesson of the leg, then actions more and more combined, and more and more secret, perhaps also less and less precise.

From the first, the necessity is therefore evident of securing the greatest precision in all transmitted 
impressions, because on the precision of these first indications will depend the clearness of the language, and in consequence to some extent the rapidity of the education. I say to some extent, because it is not sufficient that the intelligence of the horse understands the demands, it is also necessary that his will be brought to accept the exigencies, often painful, of his rider. It is also the law of association which gives the means of persuading the horse to obey; it is sufficient in effect to follow the right execution of a movement with a recompense, and his refusal with a vigorous punishment, in order to teach the horse to yield and obey.

By the repetition of this method, obedience at first hesitating, will become more and more prompt, then absolute and finally instinctive.

The training requires, in order to arrive at this last result, much kindness, so as not to irritate nerrous horses, and also much firmness, bccause it is important that the horse should consider his master the possessor of an infinite power; and this is the price of his submission. During the course of the training there arrives always the moment when difficulties appear, or a conflict arises. The tact of the rider consists in discovering the causes, viz. physical impossibility or a bad disposition. In the first case it is particularly necessary to be patient and moderate in one's demands. In the second case, on the contrary, one must enter vigorously into the fight and come out victor ; otherwise the horse, having learnt his power-still by association of sensation-becomes restive. Onc should, moreover, be careful not to be misled by the horse's resignation and be under the impression that his forees arc diseiplined. 
'The trainer should be sufficiently sensitive to perecive the signs which preecde impaticnee and revolt, and to limit and cease his demands in time. It is, besides, easy enough to aroid making a horse impaticnt, and one can make him repeat erery day the same series of excreises, providing that a certain varicty is introduced, and on condition that after each movement has been well done, a few minutes of rest are given to break the work, and induce a necessary relaxation.

In order that the education of the horse may be complete, it is not only necessary that obedience should be prompt and absolute, but also that it should be automatic. It is sufficient, when the horse's education has reached this stage, to give one of the indications, formerly closely combined, for the mechanism of association to unfold itself and provoke the execution of the morement required. At first, to obtain, and with difficulty, the start of the gallop, it is necessary to use both hands to displace the forehand, and both legs to give the position and impulsion ; later on, the closing of the fingers on one rein, and the mere touch of the boot suffices to produce this movement, because this action has recalled all the other sensations now absent.

It is by repetition that associations penetrate the memory, and consequently the operation is long. But by substituting for the repetition, or better still in adding to it, the intensity of one of the sensations transmitted, we hurry on the education. Strong impressions, though seldom repeated, impress much more quickly the associations on the mind than feeble impressions often repeated, which, according to his temperament, tire or unnerve the hor'se. 
It is by reason of these principles that the bit and the spurs, when they are rightly used, enable the period of training to be shortened. If the horse by want of attention, idleness, or bad disposition, tries to avoid doing that which one has the right to expect from him, the energetic action of the fingers on the reins, or a simple quick touch of the spur, will instantaneously recall him to the established agreement.

"To fix the associations by the intensity of one of the associated impressions is one of the keys of training" (Dr. G. Le Bon).

The principles of movement.-The locomotive energy of the horse takes the name in equitation of "forward movement " or "impulsion."

Impulsion.-The forward movement is the first degree of impulsion. This quality exists in the horse, when he answers to the first indication of the legs by extending his action without gaining sensibly in height.

Impulsion is forward movement made use of under the exact discipline of the aids, in accordance with the end desired. It is the basis of training. Its seat is in the hind quarters, which push the weight forward, or at any rate ought always to be ready to do so.

The forward movement is natural or acquired, it is natural in the case of the keen, gencrous horse, whilst in the case of the dull, lazy horse it is the result of training, and dies down the moment the action which provoked it ceases.

A rider is not really master of his horse until the latter has yielded to him his entire impulsive forces. Some horses withhold them, only giving a part of them grudgingly, and even go so far as to oppose the most complete incrtia. Other's use all their muscular 
power against the rider, resist him, or even get away from him altogether by getting behind the legs. Others give themsclves up generously, and seem to put all their power at the service of their rider. It is this result, moral as well as physical, of submission to the aids in the forward movement, which one should seck for before everything in training.

Speed is in no way a critcrion of impulsion. Impulsion shows itself much more by the way in which the horse gives himself up to his rider, than by the rapidity of his paces. I horse at the walk, trot, canter, or even the fast gallop, can lack impulsion, in the same way as another will show much, when merely walking.

This freedom in the forward walk should be carefully cultivated, not only during the training but also during the whole military life of the horse. The proper use of the forces, moreorer, brings with it the right distribution of the weight, i.e. balance, and consequently mobility and handiness.

Balance.-The muscular force and the weight of the horse are the two elements which together produce movement.

It is muscular power which produces energy. 'The body of the horse having no power of moving itself, it is muscular foree which provokes the displacement, and its employment therefore determines the good or bad distribution of weight.

The exact object of training is to control this forcein the various degrees of speed and in the changes of direction-in such a way as to oblige the horse to carry out his rider's wishes.

Theoretically, morement is determined by the different positions the ecntre of gravity takes with 
regard to the base of support. When the horse is at rest the centre of gravity is sustained by this base. The walk is nothing more than the rupture of this equilibrium, and the movement of the limbs at the right moment to support the body and prevent it from falling. Consequently the four movements, forwards, baekwards, to the right and to the left, are always caused by the centre of gravity drawing the body into one of these four directions.

In praetice one calls a horse well balanced, which moves lightly in all his paces, and is active and quick in his changes of direction.

Every horse, when at liberty, naturally balanees himself. His morements are more or less easy: the mobility which he shows proves that he is master of himself, and that he can make a judicious use of his forces.

With rare exeeptions, the moment a horse is mounted, this balance is destroyed by the weight of the rider, which displaees the centre of gravity; and in addition to this, the actions, roluntary or involuntary, of the aids, provoke numberless contractions.

Part of the museular power of the horse is thus employed in resisting the rider.

The less a horse resists his rider the better he balanees himself, and the more handy he is.

The conformation of the horse also influenees, in a great measure, the use he makes of his forees. A wellshaped horse balanees himself better under the weight of the rider, because his forees transmit themselves to the bones in the best possible dynamie conditions.

Whaterer may be the conformation of the horse, the rider should try and make him retake, as soon as possible, a natural balance, or as near to it as he can be 
brought. At first he will therefore give the horse much liberty, because in restraining his morements he prevents him from recovering this balance, which is indispensable to the proper execution of the movement.

The more steady, moderate, and conciliatory the rider is in his actions, the more confidence the horse will gain, and the sooner he will recover his balance. As the training progresses, the number of resistances diminishes : the horse, obedient to the aids, will make better use of his forces and distribute his weight better : the rider will then be able, without difficulty, to place him in the proper position for the morement he wishes.

Locomotion.-The order in which the horse moves his limbs in the different movements, and in the various paces, constitutes the object of the study of the laws of locomotion.

In the High School of riding the application of certain of these rules will bring good results; in secondary equitation one must take a larger view of the employment of the horse, so as not to enter on a course of little practical value, and likely to aggravate the difficulties.

The rider has therefore no other eare than to gire the horse the position, which should precede the execution of each morement, and give him time, of his own accord, to suitably place his limbs.

The rôle and the position of the head in movement.-When the horse disposes of all his natural means suitable for the execution of his movements, he makes use of his head and neck as a balancing pole, with the aid of which he balances his forces, or, at any rate, modifies their employment. If he wishes to go forward, he stretehes out his neck so as to draw the 
centre of gravity in the desired direction. If, on the contrary, he wishes to halt and go backwards, he brings his head in, shortens his neek, and thus eommunicates to his body the backward movement. In the morements to the side, oblique or circular, it is still the displacement of the head and neek to the right or left, which assists, regulates and maintains the turn.

The rider who wishes to remain master of his horse must place the head in such a way that the bit may be able to regulate its displacement as well as that of the neck. In this way the neck bends itself, or shortens or lengthens itself, according to the impressions that the mouth receives from the hand of the rider.

In order that the indication of the hand may be transmitted to the horse's mouth, clearly and without interfering with his breathing, his head should be in front of the vertical line. It is this position that we should make it take in the ordinary paces, and in the simple regular movements.

The more we wish to shorten the stride, the nearce should the head be to the vertical position; on the other hand, the more we wish to increase the pace, the further forward of this line should the head be.

In these two last cases, the vertical position may be considered as normal, since it is farourable to the reduction or the increase of the paces.

The head can take an irregular position, that is to say, it can be within or beyond the vertical, either on account of the defective conformation of the forehand, or on account of a badly placed bit, or owing to an excessive sensibility of the chin or of the bars, or lastly - and this is most frequently the case with horses who poke their noses-owing to a fault in the conformation in some part of the hind quarters. Not only is it 
by the judicious use of the aids that the rider sueceeds in overeoming defective positions, but also by employing a bit more or less sercre, by placing it more or less low in the horse's mouth, and lastly by tightening or looscning the eurb chain.

Thus, with a horse who pokes his nose, one should, in order to bring the head into position, increase the effectireness of the arms of the lever, and consequently use a bit with long cheeks and place it low down in the mouth; on the other hand, in the case of the horse which earries his head low, or bends his neck too much, the bit should be placed as high as possible in the mouth, and it should have short cheeks.

If, in the natural state, the position which the head takes is determined by the position of the neek, when the horse is bridled, it is the bit which, by its action on the mouth, causes the head to take a position to which the neck is foreed to yicld. It will consequently depend upon the action of the hands, whether the neck will be able to raise or lengthen itself, and to bend itself to the right or left.

Rôle and position of the neck.-The neck, being the lever indispensable to movement, its position at the point where it joins the head ought to be such, that it maintains its position, and even a certain degree of firmness from the withers to the eentre, whilst at the same time, being supple, and accepting without resistance displacement backwards and sideways. Its direction should be that which it would naturally take when the unmounted horse is standing still and balanced on his legs. If one tries to raise the head and neck too high, the play of the shoulders will perhaps become more free, but, at the same time, the loins and the hind quarters will be orerwhelmed, and 
the quarters and hocks impeded in their action; the displacements of the hind quarters will become restricted, unequal, and irregular, and, in consequence, the pace will lose both speed and regularity.

If the neck is too low, the shoulders being overweighted will make the horse heavy in hand and his control difficult; the hind quarters also, although apparently more free, will not function any the better for being freed from the weight which they naturally should carry; they will be too far away from the eentre of gravity, and so place the hind legs behind the body.

The hind quarters, when too free of the weight they ought to earry in a proper distribution of weight, are no longer able to play the part which they should in locomotion, that is to say to assist the paces by keeping up the impulsion. The neck should not therefore be either too high or too low: it shortens or lengthens itself in proportion as the head leares the vertical line. By drawing itself in, the head should bend the neck at the nape without lowering it; by reaching out it should stretch the neck without raising it. The horse being thus placed, the reins will retain all their power, the fore legs as well as the hind legs will co-ordinate their action in the movements, whether extended or cadenced, as the rider demands.

Nevertheless, when fixing the position of the neek, one must take into consideration the manner in which it is naturally attached to the body. Certain riders are mistaken in insisting on a marked elevation of the neck, in the ease of horses which have naturally a low carriage of the head. The hand, by acting thus, arrests the impulsive forces, and, by insisting on an attitude unsuitable to the conformation of the horse, 
the rider overwhelms the hocks and the loins, and the horse loses the freedom of his paces.

Lowering the head.-When the line of the horse's face is slightly beyond the rertical, the head is in the position that gives the greatest eontrol over the horse, and the rider should endeavour to obtain it from the first day the horse is bridled. In secondary cquitation, it is principally by work on straight lines, by increasing and reducing the speed of the paces, that the horse is trained to place his head in this desirable position. The legs play a very important part in this: they should always act before the hand, because the head does not lower itself, nor does the neck bend, execpt as the result of forward morement. Immediately the horse commences to go forward he meets the hand, which, by remaining fixed and low, gives the mouth a light support, which restrains the extension of the neck, fixes the head, and causes the horse to bring his chin in.

The moment the horse obeys, the legs remove their pressure, and the fingers also ease their pressure on the reins; the legs and the hands do not renew their action unless the head retakes of itsclf a defective position. The alternate effects of closing and easing the fingers of the hand, providing they do not take from the impulsion, will soon give to the neck the suppleness which it should have.

Special exercises for the young horse.-These exercises are intended to develop the power and suppleness of the young horse. They also serve to overcome any resistances which may arise.

Resistances.-Fatigue, resulting from conditioning work, and from the constraint which the young horses have to submit to during their education, provokes on their part certain resistances. These resistances 
arise either from physical defects, or from nervousness, caused by ill-advised or clumsily made demands. The principal seats of contraction are the quarters, the spine, the shoulders, and the mouth. Whether the cause of these resistances is moral or physical, it is by a rational course of exercises, directed towards different parts of the horse's body, that one succeeds in suppling and strengthening the joints and muscles. Certain movements more especially adapt themselves to the exercise of these different parts, and the instructor should regulate their use according to the result he is aiming at.

A. How to obtain the engagement and mobility of the hindquarters.-The hindquarters are the seat of impulsion, and at the same time they are a helm which causes the changes of direction.

The mechanism of the impulsion resides in the play of the joint formed by the pelvis and the thigh. It is this joint which, by closing itself more or less, and bringing the hocks under the body, enables the horse to cover more or less ground, in consequence of the more or less energy put into the action of the propellers.

This bringing forward of the hind legs lowers the quarters, and so facilitates rapid changes of direction. The hindquarters should also be able to move themselves freely to one side or the other. But, by reason of his conformation, the horse cannot execute this movement without passing, say, the off hind leg in front of the near hind leg, and in this case also it is necessary for the horse to lower his quarters and bring his hocks under the body.

The movements, which assist in obtaining this engagement and mobility of the hindquarters, are: 
the increase and decrease of speed, the halts, the zigzag line, the serpentine, the circle, the half-turn on the hindquarters and forehand more and more closely carried out, the gallop leading with the wrong leg for the turn, and the rein-back.

(a) The increase and decrease of speed.-This work comprises the following exercises:

Being at the walk : first moderate and then increase the pace. At the trot also, pass from the slow cadenced trot to the fast trot, and vice versâ.

When standing still: start into the walk, halt, walk fast, and then again halt.

When walking break into the extended trot, and then halt.

It also comprises the start into the eanter from the trot, walk, canter, halt, and rein-back; the change from the gallop to the trot, walk and halt, and the increase and decrease of the speed of the gallop.

The horses have learned, whilst being broken, to answer to the hand by decreasing the pace, and to the legs by increasing it. The rider returns to, and insists on this lesson, until the horse slackens his speed without the least movement of the head to indicate resistance to the hand, and increases his speed without the slightest hesitation. Every time that a horse fights against the hand, when being checked in the fast paces, he should be put back to the walk, and be made to increase and decrease his speed. When once obedience has been obtained, the rider studies the way in which the movements are made: the hind legs are brought under the body when reducing the pace, and the hocks and loins are stretched out when the speed is increased. This is attained by alternately increasing and decreasing the pace at shorter intervals. 
This result obtained, the rider will demand more decided variations in the speed, and will bring his horse to the dead halt in the fast paces.

In this work, which consists in balancing the horse between the hand and legs, it is essential that these two aids should not act together. The horse when slackening his speed should reduce pace without raising his action; and on feeling the pressure of the legs he should drive himself freely forward. If he raises his aetion, it will be because the hand has not yielded in time to let the impulse pass.

If the horse, when reducing his pace, turns sideways, he should be straightened by opposing the shoulder to the quarter.

These suppling exercises are varied by periods of fast work, with the support of the hand. It is advisable to especially insist on immediate obedience in increasing the speed in the ease of sluggish horses, and in reducing the speed in the case of keen horses.

When the work has been well done on the straight line, it should be repeated on the circle, so as to secure a thorough engagement of the inside leg. The diameter of the circle will be reduced as the education of the horse progresses, but one should not allow the horse to decrease, of his own accord, this diameter at the same time as he decreases the speed, that is to decrease it when reducing the pace, and to increase it when accelerating it.

In the school one only executes the changes of pace in the slow canter; out of doors, one demands that the speed should be varied in the canter, and fast gallop equally, and the capability of doing this is the proof of the results of all the preeeding work.

If the horse bores and fights against the hand, he 
should be taken back to the school, and taught to stop in the walk and slow canter. In this way one succeeds with less risk to the limbs, and more surcly, than il one persevered, till obedienee was obtained, in the work at the fast paces.

(b) The halt. The half-halt.-The halt looked at from a training point of vicw is not only useful to immobilize the horse, but more especially to teach him to balance himself by bringing his hind legs under the body.

The halt is brought about by the finger's gripping stretched reins. If the hocks remain behind the body, or the quarters throw themselves to one side in order to avoid an engagement, which is always painful at first, the rider's legs should be elosed, in order to gently press the hind legs under the body, whilst the hand remains passive.

The halt gathers together the forees of the horse, fixes his head and his quarters, and makes him light in hand.

One should practise the halt rery progressively, and at first with great gentleness. Being especially temperate with horses having ewe necks, and those which are long in the back, saddle backed, or ncrvous. These sort of horses, being generally weak in the loins, take the halt with difficulty, and the remedy becomes worse than the evil. One should not halt suddenly horses which lack impulsion. In fact, the sudden halt really only suits horses with strong loins, and sufficient strength in their quarters and hocks to bring themselves to a halt sharply on their hind legs.

This is not the case with the half-halt. The halfhalt, which has been explained in the chapter dealing with the aids, irritates the horse less than the halt : one 
can therefore use it without fear with all horses, except those that are behind the hand.

The result sought for is to raise the forehand and consequently to lower the hindquarters without cheeking the pace.

(c) The zigzag or broken line, the serpentine, the circle.-When the turns are demanded by the reins only, acting on the forehand, they not only supple the shoulders, but they equally favour the engagement of the hind legs. These same movements, when the leg presses the quarters to the outside, give great mobility to the hindquarters; it is therefore necessary, when they are used, to know what one wants, and to carry them out with a view to the result desired.

The search for mobility in the hindquarters aims at keeping the horse on a straight line and in making turning easy. There resides in the hindquarters, together with all the impulsive power, the source of nearly all the resistances, and consequently, if one wishes to overcome these resistances, the obedience of the hindquarters must be prompt and absolute, and show itself by the striet obedience to the leg.

(d) The half-volt, made more and more closely, draws the hind legs more and more under the body. 'The half-turn on the quarters, which is the limit, gives the last degree of this engagement.

The half-volt on the forehand, made more and more closely, helps to mobilize the hindquarters. The half-turn on the shoulders, which is its limit, gives absolute mobility to the hindquarters, which turn round the forehand.

(e) Canter with the wrong leg leading.-The rider trains the horse to canter on a circle, leading with 
the wrong leg, by cantering on a broken line, and making the turns progressively sharper without a change of leg. He then attempts the figure of eight and the serpentine. He commenees work on a figure of eight by a large eight between the two ends of the riding school, executed once only (two changes of hand). As soon as the horse can do this ealmly, the rider should keep him on the figure for a longer time, and when he eanters ealm and free, the size of the figure should be gradually reduced. He should, however, work the horse frequently on the large figure, in preference to the smaller ones, especially in the case of underbred horses.

In the same way the serpentine will at first only have one bend, and the number of bends will be gradually increased as the horse gains experience.

This work makes the horse modify his balance of his own accord, and gives the alternate extension and engagement, which is the object of this exercise.

To avoid the needless difficulty of starting the turn leading with the wrong leg, the rider should start with the proper leg leading, and then change. During the turn on the wrong leg, the inside rein, by a careful opposition, keeps back the inside shoulder and quarter to prevent the change of $\mathrm{leg}$. This opposition diminishes as the horse makes the turn on the wrong leg more réadily.

( $f$ ) Rein-back.-Although backing is especially a punishment for the horse, which, notwithstanding the halts and half-halts, tries to foree the hand, or to lean unduly on the bit, it is equally an exercise which helps to supple the spine, and makes the horse balanee himself on his hind legs. 
Reining back is another step in the exereises which aim at alternately increasing and decreasing the base of support.

The exercises in increasing and decreasing the paces, which the young horse undergoes, generally make it easy for him to move backwards.

The horse may, nevertheless, owing to pain or a bad disposition, refuse to go backwards. He fixes himself on his hind legs, contracts his spine, and resists the action of the reins.

To overcome these bad positions, in which the horse is behind the hand, the rider should displace the quarters to the side with his legs, or alternately oppose each of the shoulders to the corresponding hindquarter, and he will profit from the displacement of the quarters to again use his hands.

In the execution of this movement the horse should be calm and straight, and he should walk slowly and be always ready to move forward again to the pressure of the legs. At first, especially with keen horses, it is advisable, after pressing the horse forward again, to slacken the reins completely and give him ease.

When these results have been attained, one tries to obtain a change more and more smooth from the forward to the backward movement, and vice versâ; one should balance the horse between the forward and backward movement by making only a few steps in each direction.

B. How to supple the spine.-The suppleness of the spine is obtained by the exercises already mentioned, but especially by work on a small circle at a canter gradually increasing in speed. It is the best of suppling morements to the side, and one should make frequent use of it. 
The horses being on a circle at the canter, the instructor, in order to aroid the fatigue caused by long continued work on a short turn, should enlarge and decrease the size of the circle every few turns, and counteract the tendency of the horses to slacken their speed in proportion as the circle becomes smaller. The sharp turn at the slow eanter is easy; that which is diflicult, and which must be obtained, is the sharp turn at a fast pace.

C. How to develop the free play of the shoulders. -The horse which, when at liberty, goes through crolutions with ease, and balances himself without diffieulty, becomes generally heary on the hand the moment he is mounted; this change arises partly from the distribution of the rider's weight, and partly because the horse balanced himself for movements which he himself wished to execute, whilst he does not yet know how to balance himself for morements which his rider requires of him.

The most suitable exercises for giving mobility to the shoulders, and consequently developing the lightness of the forehand, are, the slackening of the various paces, the halts and half-halts, backing, and especially the zigzag line and the serpentine, in which the turns are demanded by the reins only, causing the shoulders to turn round the quarters, the circle with the croup on the inside, the half-volts-more and more restrieted till the horse makes the half-turn on the quarters-the double changing of hand, and moving sideways with the shoulder in. There is good reason for specially working on zigzag lines at the canter, the number of strides between each turn being gradually decreased, the horse making the turns without changing his leading leg. This is the best lesson for 
making the horse supple and active in his canter and gallop, easy to handle, and clever on bad ground.

The different movements which have just been mentioned should be demanded by the indirect rein, which acts effectively on the shoulders. Of course, these movements do not possess, in themselves, a special power leading straight to the end desired; the rider must apply the right aids according to the end he has in view and the resistances which he meets with, and he must act with tact, that is to say, with more or less energy or gentleness according to the circumstances.

At first, in order not to discourage the horse, these different movements may be large and even irregular, but they should become more and more confined and precise, in order to bring about the complete obedience to the aids, which is indispensable in single combat.

During all the work, the greatest care must be taken to preserve the forward movement, and the rider should always, after closely collecting his horse, allow him to relax his muscles, by extending his stride, before giving him rest, so as to avoid any loss of impulsion.

D. How to supple the lower jaw.-The suppleness of the lower jaw is the visible sign of perfect balance; it indicates a general relaxation of the muscles. In the case of a horse with a normal mouth, the excreises which supple and strengthen the young horse produce this mobility of the jaw, which is to some extent the proof of willing obedience. But some horses, though the rest of their body may be supple, maintain an abnormal stiffness in the jaw.

The cause of every resistance is pain. The contraction of the lower jaw may be eaused by a bit which does not suit the horse, either because his mouth is too sensitive for the bit, or, on the contrary, because 


\section{'TRAINING}

its sensitiveness may have been deadened to such an extent that it cannot feel the effects of the bit. 'The first remedy consists, in this ease, in the eareful choice and fitting of the bit. The shape of the bit, its position in the mouth, the length of the cheeks, the thiekness of the eanons, the height of the port, the length of the curb chain, help to orercome many resistances.

Nevertheless, owing to the aetion of a brutal or simply clumsy hand, the most carefully bitted horse will form habits or take positions which are veritable resistances, beeause they cnable him to avoid the constraint of the bit. It is therefore neeessary in these particular cases, to recommence the education of the mouth with the help of appropriate suppling exereises, intended to destroy the bad habits and to replace them with good ones.

A horse is said to yield to the hand when, being in light contaet with it, he slightly opens the mouth ou feeling the fingers elose themselves on the reins, and mores his tongue and the bits for an instant, and then immediately resumes contaet with the hand. The cession should be confined to the mouth, and should not be accompanied by any morement of the head or neck.

The first elements of this excreise can be taught on foot and at the walk; but as at this pace, with the instruetor on foot, the impulsion is at the best fecble, the employment of this method may be dangerous in secondary equitation.

To obtain the desired relaxation, the rider should put his horse into an extended pace, and by the gentle fixity of his hand, he will strive to obtain a eonfident feeling, with the earriage of the head and neck which is usual to the horse, although it may be a vicious 
attitude. 'This result having been obtained, the rider will have recourse to an intermittent feeling on the mouth, by easing one bit and closing the fingers on the reins of the other one, by drawing the bridoon lightly from side to side, or by simply easing and closing the fingers on the reins. These various actions tend to baffle the resistance, by constantly changing the support, and overcoming the contraction of the muscles by keeping them constantly mobilized.

According to the nature of the resistance, the halfhalt or vibrations, administered through one or several of the reins, will cause sooner or later the relaxation wanted. When, in consequence of the repetition of these exercises, the horse obeys without hesitation, and when every combination of the reins secures the same submission, the education of the mouth is finished.

The advantages derived from the relaxation of the lower jaw are the effects produced on the nape of the neck, and on the neck itself, the muscles of which soon also relax themselves. The neck first takes its natural position, and then, owing to progressive exercise, it arrives at the position that gives the face a vertical line, and makes the control of the horse casy. When practising the suppling exercises of the mouth, the rider must take every precaution to preserve the impulsion, and he should not recompense a coneession by reducing the pace, but by slackening the reins, patting the horse, and pressing him on in a brisk pace.

The rider must, if necessary, limit the employment of this local exercise, and not lose sight of the end sought in training as a whole, namely, the harmonizing of all the forces of the horse.

Movement to the side and "shoulder in."-The movenuent to the side, carricd out with the lateral 
aids, is a movement which is applicable in the management of the horse, when either ridden by himself or in a troop.

When the horse is walking with the wall on the left, the side movement is obtained by the left rein and leg, which act by pressing the shoulders and quarters towards the right, the horse is then bent to the side opposite to that to which he is directed.

In this movement the shoulders and quarters travel over two parallel tracks, so that in moving to the right, the near fore and the near hind cross in front of the other legs, and the reverse when moving to the left.

In training, the side morement is useful to bring the horse to understand the effects produced by the combined aids, and, in addition, it is an exeellent exereise for the young horse. The rider should only demand this morement down the centre of the school, or when working across it diagonally, and only for a relatively short time. When carried out on the track near the wall, the side movement has the inconvenience of getting the horse in the way of guiding himself by the wall, instead of obeying the aids. Besides, it frequently happens that the horse, not being able to pass the outside leg in front of the inside leg for fear of hitting it against the wall, passes this leg behind the other, which does not give the desired result.

If, by a stronger action of the aids, the rider slightly increases the displacement of the forchand, in respect of the hindquarters, the horse changes from the excreise of the side movement to that of the "shoulder-in."

The horse is said to be on the "right shoulder-in" (inside of the are of a circle formed by the spine) 
when he moves bent to the right; and on the "left shoulder-in" when he moves bent to the left.

No matter the hand to which the rider is working, or the part of the school he is in, the horse can thus be placed and work indifferently either on the right or left shoulder-in.

The movement is carried out at the command"Right shoulder-in-Go large." " Left shoulder-in-... Go large."

To place the horse on the right shoulder-in, for instance, and to work him in the most favourable position, the rider removes the shoulders from the line being followed by an action of the right opened rein strengthened by the leg of the same side, and thus starts the horse turning. Immediately the horse is in this oblique and circular position, the rider continues in the direction previously being followed, whilst keeping the horse bent in the form of a crescent. The right rein now becomes the indirect rein of opposition, acts in the direction of the left quarter, and affects the whole body of the horse, which it curres and presses forward, and to the left.

The right leg, by closing in near the girths, assists the movement by also displacing the quarters to the left. The left hand first yields and then limits the bend of the neck, and then strengthens the action of the right rein, by also drawing the forehand forward, and to the left; the left leg, which is closed in against the girth, maintains the forward movement. This movement gives the horse the greatest suppleness and freedom in all parts of the body.

It creates-

1. Freedom of the shoulders, obedience to the hand, and consequently lightness of the forehand. 
2. Suppleness of the hindquarters, obedience to the leg, and consequently the engagement of the hindquarters.

3. Flexibility of the spine, which harmonizes the forehand and hindquarters.

\section{(Part left out merely explanation of above.)}

The "shoulder-in" is therefore the synthesis of all the gymnastic movements that one can demand of the horse, and it is, as La Guerimere used to say, "the first and last of all the lessons one can give a horse." Its execution is easy, and the results excellent and rapid. It is necessary, as in the case of the side movement, to avoid earrying out the "shoulder-in" on the track near the wall, as the horse is always attracted by the track, tries to get back to it, and only bends his neek instead of yielding his shoulders, which is contrary to the end one has in view.

The "shoulder-in" is taught at first on the circle, and the rider gradually trains the horse by taking him away from it for a few steps: he then pats him and recommences again further on.

When the horse understands what is wanted of him, and carries out the movement all right at the walk, it is repeated at the trot.

For the proper execution of the movement, it is necessary that the hand which keeps the shoulder in, should act fixedly on one rein, held short, and the rider should especially avoid drawing the rein backwards.

The horse should be frequently exercised in the shoulder-in, and should be worked alternately on one shoulder, and then the other, the rider being careful between each change to walk for a few paces on a straight line. These suppling exercises should only 
be given for a short time, and the rider should profit from the engagement of the hind legs to press the horse forward in a vigorous extended trot after straightening him, the hand only giving the head and neck the support necessary to assist the extension of the legs.

Easing of the hand and extension of the neck.The easing of the hand, defined and commented on by La Guerimere, and later on adopted by the Baucher school as one of the fundamental principles of equitation, is nothing more than the proof of good balance. It consists, after having placed the horse in a certain balance, in withdrawing, at first for a few moments, and then for a gradually increasing period, the action of the legs and hands, and accustoming the horse to remain in this balance, without the assistance of the aids, and without decreasing his pace.

The longer the horse remains collected in this position, the more he shows the perfection of his condition and of his balance-natural and acquired -and the completion of his training, whether as a charger, a hunter, or a High School horse.

The easing of the hand does not of necessity imply that the legs should be entirely removed, or the reins quite slack, but the action of the aids should confine itself to simple contact.

In this position, the horse enjoys an independence favourable to the economy of his power, and his initiative is aroused.

Although inapplicable at ficld practice or during manouvres, because the changes of pace and direction demand from the rider a frequent and often energetic use of the aids, and consequently on the part of the horse a constant position of attention, onc should nevertheless ease the hand whenever there is not 
this necessity, as, for instance, when on the road, or on an individual mission, or when taking a ride alone.

The extension or lowering of the neck is quitc different from the dropping of the hands.

It is evident that the considerable part the neck plays in the movement of the horse at liberty, makes it neecssary for the rider to be master of the lengthening and shortening of the neek, if he intends to have it in his power to regulate the movement aceording to his wishes.

When the training is properly earried out, the connection between the rider's hand and the horse's mouth ought to be regulated, from the first, by making the most of the natural attitudes indispensable to movement, and yet maintaining in the horse the respect for the hand.

In course of time, whenever, after getting the horse in hand, the rider yields progressively the hand, whilst the legs continue to act, the horse should seareh for the bit by lengthening his stride. The rider's tact will now show itself in finding and giving to the horse the support which will be best for him for lengthening his stride, changing the paee, jumping, etc. It is no longer the dropping of the hand, it is teaching the horse that when the rider continues the pressure of the legs and at the same time progressively eases the hand, he should lengthen his stride, lower his head and demand from the hand the support and assistance necessary. The rider brings the head back into place with the reins, and, the hand having then more action than the legs, there will be of necessity a reduction of the pace; after the horse has lengthened his stride and then collected himscll into a slower 
paee, the hands should be eased without the horse altering his balance. It is by these alternate manifestations of submission, and these periods of liberty, that horses become light in hand and always keen.

The movements of the walk and the halt, as well as the lengthening and slackening of the pace, should be carried out with young horses in such a way as to promptly and clearly establish this understanding between the rider and the horse, and they suffice nearly always to bring about that light connection indispensable to the changes of pace and direction, and, consequently, to the extension and drawing in of the neck necessary to movement.

But, with certain horses, who get behind the bit, fear the hand, or are ewe-necked, special exercises are necessary, which require tact and patience, in order to get control of the play of the neck, and to place on the shoulders the weight they ought to carry. It is by working on a circle with impulsion, in alternating the effect of each bit, by mobilizing the fingers, and by vibration of the reins, that the rider succeeds, little by little, in getting the horse on the hand, then to taste the bit, and lastly to extend his neck either forwards or to the side. One must not confound the extension of the neck, which is a slow progressive aetion, with the movement of the horse which plunges forward suddenly and snatches at the reins; nor with the immediate and complete abandonment of the reins, accompanied by the easing of the legs, which follow the proper execution of a movement: the first is a defence which must be defeated at once, the second is the reward and rest, which the obedient horse deserves.

Balancing.-In the extension, slackening, and 
change of the paces which have been studied, the rider must be eareful not to enclose his horse between the legs and the hand. 'The rule remains invariable for the rider to keep his horse impulsive, and at the same tine obedicnt, by the right action of his hands and legs. But, in proportion as the training advanees, these actions tend to draw together, and at times to be simultaneous. 'The horse, thus balanced between the legs and the hands, works in a sort of balance with his neck and action high, that is to say, in a state of collection.

Collection in morement aims at shortening the base of support of the horse, which then works on a short base, which increases his mobility, whilst necessarily reducing his speed.

Whenever the rider wishes to return to an extended pace, he should cease to demand collection, and let the impulsion pass forward; at the same time the neek extends itself, the pace increases, and the horse again works on a long base.

To oblige the horse, according to circumstances, to work on a short or long base, to accustom him to change from the most closely collected work to the roughest country riding--in a word, to balance himself, is the aim of military horsemanship, and it is to the attainment of this end that the changes of pace, the increase and decrease of speed, with which we have been dealing, tend.

Observations on the paces.-One can gather from the mechanism of the walk, the trot, and the gallop, observations very useful in training.

It is of the greatest use for the rider to know how to start a pace at the command, and to maintain or change it. Now, in the walk, and in the trot, the 
lateral bipeds move parallel to one another: in the gallop, on the contrary, the horse places one of his quarters slightly to one side. 'This remark is neeessary, and it suffices to explain to the rider that at the walk and trot, the horse should remain absolutely straight, whilst at the gallop, he yields slightly one of his quarters. Every time that the rider wishes to start the canter or gallop with a young horse, he should first give him this natural position. On the other hand, whenever he wishes to ehange from the gallop to the trot or walk, he has merely to replace the horse in the straight position.

Another obligation imposed on the rider, consists in developing paces which enables the horse to go long distances without fatigue, and, in order that the horse may employ as little energy as possible, it is essential that the impulsion acts in the direction of the movement.

The horse moves with high or low action, according to the way in which he is ridden; he ean also move high in front and low behind.

"The horse will move with high action when, suppled and trained by exereise and properly ridden, he can be collected when moving. Then the muscles of the neek, being bent and high, will raise the forelegs by their contraction, whilst the hind legs being well under the body also flex themselves" (General de Benoist).

Thus placed the horse cannot develop any great speed, because his action loses in extension what it gains in height, and moreover, his joints are constantly being flexed, but this position is very favourable to instantaneous changes in the balance, and consequently in dircetion and pace. This collected position has, thcrefore, a frequent use in sceondary equitation, 
since whether at manœurres, or in single combat, the horse must be able to work on a short base.

The horse mores high in front and low behind when, ridden by an inexperienced horseman, he carries his head high either from choice or constraint, and as in the preceding case, the museles of the neck raise the forelegs by their contraction; whilst the hind legs, placed far from the centre, are not able to engage themselves, their morements will be jerky and the spine will not have any flexibility. The horse will consequently move with a considerable expense of energy and discomfort in the loins and hind legs, showing itself by all kinds of disorderly movements.

Finally, the horse will have a low extended action when he moves with the neck stretched out in a horizontal position. The museles of the neek will then draw the forelegs forward instead of upwards. The hind legs, answering to the pressure of the rider's legs, will be able to bring themselves well under the body in consequence of the position of the neck, which enables the spine to easily arch itself and then spring back in the direction of the morement.

This position will, therefore, be favourable to speed, and all the efforts of the horse will tend to produce the movement with the least fatigue, since no energy is lost. It is, therefore, this position, which the rider must try and make his horse take, whenever he is working alone, or on a long base.

Considered from the point of view of training, the paces, which have already been taken advantage of in the breaking, offer the following further uses.

The free extended walk constitutes a rest to the horse; it is consequently the best reward the rider can give him, to show his satisfaction after the good 
execution of the morement demanded, and he should make frequent use of it.

Furthermore, at this pace, the seat being firm, the rider is in possession of all his means of action, and should make use of it to rectify all the bad positions of his horse, and to teach him the positions which preeede the carrying out of every new movement. The horse, being all the more disposed to obey as the action of the aids is more decided, and all the more master of his balance as the pace is less rapid, finds himself thoroughly prepared to receive the lesson. Every new movement, and every new position, should therefore be learnt at the walk before it is attempted at the fast paces.

But at the walk. precisely because of the slowness of the pace, the effects of the exercises on the joints and muscles, especially in the movements to one side, are but slightly marked. In the same way, if, at the canter and gallop, the increase and decrease of speed is an excellent exercise for the spine, the morements to the side on two lines, on the other hand, have no useful effect on the horse, because in this morement he mores in a series of parallel bounds, without any of the legs crossing one another, and consequently without great effort.

In the trot, on the contrary, in consequence of the mechanism of the pace, the morement on two lines is a gymnastic excreise all the more efficacious in proportion as the impulsion is greater, and the action more extended. In order that the near side legs, for example, may streteh frecly to the left, and that the off side legs may pass in front and cross orer them, the horse must more in big strides, and consequently maintain his speed, otherwise there will not be any vigorous working 
of the museles and joints, in a word, there will be neither gymnastic excreise nor impulsion.

The start of the canter or gallop.-The importance of the gallop makes it necessary that the rider should know all about this pace; because the way in which horses commence it, keep it up, modify or leave it, has a great influence on its exceution.

Besides this, the study of a complieated morement, which ealls upon all the knowledge of the rider, and finally upon the absolute obedienee of the horse, gives the opportunity for applying to a concrete case the principles laid down in training, and for showing in detail the rôle and value of the aids. To analyse completely the start of the canter, is to make a synthesis of all the training, and to show by the study of one movement, how all the rest can be obtained.

The horse, when at liberty, starts the gallop in several different ways. As a general rule, he begins this pace according to the causes that make it neeessary, at one time by a slight loss of balance, produced by his throwing his weight forward, at another time, by his throwing back the weight of the forehand on to the quarters, that is to say, by bringing his hind legs under the body and balaneing himself.

When mounted he acts in the same way, when a cause, out of the control of the rider, starts him into a gallop (a click of the tongue, the whip, or fear).

When the rider wishes to start his horse into a gallop by command of the aids, it is neeessary to take into consideration, when making choice of his means, the effects which the hand and the legs may produce, since according to his state of training, the horse may only understand a part of the effeets of the aids.

In order to make the horse understand that the 
sensations that he feels demand the gallop, it is necessary to place him in a position which, by removing all hesitation, leares him nothing else but a definite movement to be carried out : the one that is required of him.

Whether the horse starts the gallop by loss of balance or by balancing himself, the position should always precere the movement.

It is the very mechanism of the gallop which indicates the position which the horse should take. The gallop is characterized by the advanced position which one lateral biped takes with regard to the other, that is to say, that in the gallop to the right, the two offside legs move in advance of the near side legs and vice versâ.

A. With young horses which are ignorant or imperfectly trained to the aids, and have nevertheless to be galloped, in order to develop them and advance their condition, the rider should put them on to some circular movement in which the lateral biped on the inside, having less ground to cover than the biped on the outside, is able to take with greater ease the forward position. By making use of the action of the reins already explained, and by pressing the horse forward more or less energetically with the legs, the horse, being thus placed, will break into the gallop quite naturally, especially if the rider leans his body slightly forward, and to the right for the gallop leading with the off fore, and inversely for the gallop to the left.

The horse, to some extent surprised, and thrown forward by the action of the legs, falls into the gallop to the right.

The rider has taken advantage of the farourable 
position taken by the horse himself to start the gallop. In this way the horse becomes used to this pace combined with the weight of the rider. With practice, the starts become more and more easy, and the horse enters on the gallop voluntarily, and with increasing lightness.

Such is the first part of the lesson in the gallop. This method of starting is suffieient for giving to the young horse the necessary work; it is, moreorer, the only one which can at this time be employed, since the horse is ignorant of the action of the aids.

B. But the rider does not always start the gallop from a curved line: he must be able to start with changing direction, that is to say from straight lines. The work which brings about this result constitutes the second part of the training, in which the rider must be able, at his wish, to place the horse in the position which commands the gallop. The horse must therefore be taught the elementary action of the aids.

To start with the off fore leg leading it is necessary to restrain the near side legs, or to advance the off side ones. Now, to obtain this result it is sufficient cither to restrain the action of the left shoulder, whilst freeing at the same time the right shoulder, or to place the left quarter slightly to the right, or to bring the right quarter forward slightly in advance of the left.

All the actions of the reins or of the legs which will bring about these results are right, although in different degrees, and will prepare the horse, according to the state of his training, to start on the desired leg.

1. To restrain the left shoulder, the rider must 
resist with the left rein, either by a light direct effect of opposition, or by an indirect effect of opposition, employed, one or the other, according to the nature of the resistance.

2. By assisting one of these actions of the left rein with the left leg, the rider obtains a deviation more or less pronounced of the left quarter towards the right, and places it behind the right quarter, in the position for the gallop leading with the right leg.

3. To obtain the start of the gallop by causing the right quarter to advance, the rider must use his right leg against the girth, so as to bring the right hind leg under the body (High School Riding). Of course the rider can combine these various actions in order to obtain an effect more quickly and accurately. W'hen once the position has been obtained, the rider has merely to give the impulsion necessary for the speed of the gallop by an equal pressure of both legs.

The start of the gallop to the right, by the resistance of the left rein, is very simple and irresistible; it is the method employed during the carly part of training, and generally whenever the rider finds any difficulty in getting his horse to start on the desired leg.

The start of the gallop to the right, by the predominant action of the left leg, has the inconvenience of forcing the horse off the straight line, and, if the horse starts with an excessive action of his inside leg, he may start false.

The start of the gallop to the right by the predominant action of the rider's right leg, pressed in against the girth, is eertainly the most correct, since the horse starts straight; but this effect of the leg is rather the result of education than natural. This method of starting the gallop can only be employed when the 
training is nearly finished, and should only be attempted by experienced horsemen having precision and tact, and with horses which are calm, obedient, and sensitive.

The rider should make frequent starts on one or the other leg, in order to get the horse accustomed to them. It is for the instructor to judge as to what he can, or ought, to demand. The only rule to fix firmly in the mind, is never to require anything of a horse until he has recorered ealmness, and, on the other hand, never to cease work with a badly carriedout morement. IVe have only dealt here with the determining aids, which do not, however, exclude the other aids. These, by regulating or strengthening the demand made on the horse, give great assistance to the regular and prompt execution of the movement.

To sum up, the progression we have followed is that from the known to the unknown, that is to say, in teaching the start of the gallop only to use the effects of the aids which the horse is able to understand, according to the advancement of his training.

To make use of, at any rate at first, the positions which a horse assumes when at liberty, and only to modify these little by little, while constantly bearing in mind the necessity of substituting the straight position for that with an inclination to one side, and the well balanced instantaneous start for an uncertain disorderly one.

To change from the eanter to the trot, or from the canter to the walk, the rider must replace the horse in a perfectly straight position: when thus placed the horse will modify the combination of his legs and resume the trot or the walk.

When onee the gallop has been checked, the rider should press the rcins with the fingers more or less 
firmly according to the pace he wishes the horse to take, and the rapidity with which he wishes the change to be made, it being borne in mind that, whilst the legs remove their pressure, they should nevertheless remain in contact with the sides, ready to close in again to maintain the forward movement as soon as the horse has taken up the new pace.

Jumping when mounted.-The horse should be regularly exereised with the object of making him clever over rough ground and free at his jumps. Calmness is also an indispensable quality in a riding horse, and the trainer should endearour to obtain it by every means in his power, especially by developing calmness in himself.

The work on the lunge, carried out either in the school or out of doors, is an assistance too important in this part of the training to be neglected. It should be frequently resorted to during training, but one of the best means of obtaining freedom and calm, when a horse is ridden at an obstacle, is to regulate the pace according to the size of the jump and the nature of the difficulties. To ride at a pace too fast is to waste energy and to invite disaster, but towards the end of the training the horse should be brought to jump the obstacles, large or small, that he meets, at the fast paces, without getting excited, and without checking his speed.

As in the case of the young horse; it is skill and willingness, rather than power in jumping, that ought to be developed during the training. Consequently, this instruction has the most useful application in the open, over natural and fixed obstacles.

To give a young horse his first lessons in the school over movable jumps is to teach him to despise that 
which ought to be respected, and to ask him to show a willingness which the aids of the rider, at any rate at the commeneement of training, cannot enforce, in ease of refusal.

Practical outdoor horsemanship enables one to group the difficulties which the horse offers, when being ridden over jumps, in a small number of defences, which need only be known to be promptly remedied. Experienee has also proved that, in most eases, the horse limits his resistanees to one or two defences, which he invariably makes use of.

When a horse refuses to jump, the first thing for the rider to do-as also for the instructor, who in case of necessity should point out the remedy, or take the place of the rider-is to consider the nature of the defence.

If the horse has shown on the lunge suffieicnt power, and if his edueation has been properly carried out, there can be only two reasons for his refusal to jump when mounted: either he refuses to obcy the aids, or the rider has not sufficient tact. In the first case it is best not to insist, and to perfect the training, before recommeneing the jumping lessons.

If the refusal is eaused by want of skill on the rider's part, it is suffieient in most cases to explain to him the fault he has made, in order to obtain the immediate obedience of the horse.

The different ways in which a horse refuses to jump can be grouped as follows:-

(a) The horse stops short.

(b) He turns off some distance from the jump.

(c) He swerves when near the jump.

(a) If the horse stops short it is owing to want of impulsion, or lear of the rider's hand. When there is 
want of impulsion the rider should leave the jump for the time being, and again give the lesson of the legs, and, if neeessary, that of the spurs also, and then when he feels his horse keen to go forward, he should send him again at the jump, keeping him ealm and straight, and press him forward with the legs the last few strides; when the horse has jumped he should dismount and pat him.

If the horse refuses from fear of the hand the rider should first alter the bit, if neeessary, and then lower the bar, or if in the open, choose small jumps, taking them at the walk or slow trot, with long reins, giving perfeet freedom to the neek; the rider ean help the horse, if neeessary, by taking hold of the pommel of the saddle, whilst jumping, to restore the confidence of the horse in the hand, and eneourage him to streteh out his head and neek.

(b) The horse who refuses some distance from the jump, takes sudden hold of the rider's hand, places his head and neck in a position which enables him to avoid the action of the bit, and makes his escape to one side or the other.

The rider, in this ease, should divide the difficulty into its component parts: get his horse into hand again, calm him, and, after placing the head and neek in their proper position, put him at the jump again, holding him firmly till the last moment, with strong pressure of the legs, and stretched and firmly held reins.

(c) When near the jump the horse refuses either by throwing one shoulder out or by turning sideways and moving with the quarters in front of the shoulders. In the first ease, the rider will draw back the leading shoulder by opcning his reins, if the horse 
merely attempts to shy off; or by the energetic use of the indirect rein, if he throws his shoulder vigorously out of the line; and by pressing him strongly forward at the same time with the legs.

In the second case, that is to say if the horse refuses by throwing his quarters out, for instance, to the left, the rider will use the lateral aids, and place the horse on the left shoulder in (left indirect rein of opposition and left leg), and will thus press back the quarters into the right direction. It is true that the horse's head is placed in the direction to which he wishes to turn, but, under the action of the left rein and leg, the whole body is foreed towards the right. The rider will straighten his horse again at the last moment, and the impulsion, stimulated by the rein on the side. of the inside shoulder, combined with the energetic use of the legs, drives the horse frecly at the jump.

All the defences which have just been analysed are always preceded, at one moment or another, by a sudden abandonment of the hand by the horse, who profits by this moment of liberty to take the position he prefers for resistance.

The rider when approaching a jump should, therefore, always attentively feel with his seat and legs the morements of the hindquarters, the seat of impulsion, and keep the reins stretched, so as not to lose contact with the mouth and keep in close touch with his horse. 


\section{THIRD PART}

\section{APPLICATION OF THE PRINCIPLES OF HORSEMANSHIP AND TRAINING TO THE CONTROL OF 'THE HORSE}

\section{CHAP'TER I}

THE EMPLOYMENT OF THE TRAINED HORSE BY THE TRAINED MAN

As a consequence of the breaking-in, the horse has become calm and impulsive.

His suppleness and strength have been developed, and his resistances have been overcome, by the special exereises of the training course.

During this work the horse has learnt to obey the aids. It now remains to apply, in the daily work, the results attained.

The following rules serve as a basis on which instruction in horsemanship can be perfected.

The straight-moving horse.-The first use made of this obedienee has for its object to make the horse a straight mover, firstly, beeause of the place he ought to occupy in the ranks, secondly, because this position is of great use in obtaining the pace desired, and in regulating the speed.

'The horse is straight when the left shoulder and 
the left quarter, the right shoulder and the right quarter, are in line with one another in the walk.

In horsemanship it is also right to say that the horse moves straight, although he is working in it circle, when the shoulders and the quarters move at the same distanee from the eentre.

When the horse is straight, the hind fect follow exactly the lines traced by the fore fect; the quarters and the shoulders are so placed as to insure the trueness of their reciprocal action. The two quarters move equally, the impulsion is equally distributed, and the transfer of weight from one part to another is regular and easy. The forces which emanate from the two ends of the horse do not experience any contradiction in their combined action, and work for a common end, i.e. movement in a straight line for which the horse finds himself perfectly placed.

If, instead of moving straight, the horse mores obliquely, harmony no longer exists between the forces of the hindquarters and those of the forehand, there is no longer true distribution of the weight, and the equal facility of moving to either side; moreover, the quarters are bent round and oppose the shoulders, and consequently resistance is experienced. There is therefore good reason, before attempting anything clse, for placing and keeping the horse straight. The action of the reins and of the legs, which has already been studied, enables the rider to bring the horse back into a straight position. In referring to instructions already given, especially to those regarding the effects of the rein of opposition, and by making use of the assistance which the legs give the hands, the rider will find all the necessary combinations to redress the shoulders, force back the quarters, and maintain, 
and if neeessary, bring back the horse to the right direction.

But, to obtain the result which the right use of the aids should give, it is necessary to maintain the vigour of the impulsion. True, free, easy paces, depend entirely on the activity of the quarters and the straight position of the horse.

To change the pace, and in any given pace to change the speed.-'The execution of the changes of pace rests on two principles.

1. When the legs close in to press the horse forwards, the hand should not oppose the movement ;

2. When the hand acts to moderate or to annul the impulsion, the legs should be passive;

consequently, to start the walk from a stationary position, to extend the walk, to change from the walk to the trot, to lengthen the trot, the rider should apply the legs with more or less force, according to the result he wishes to obtain and the sensibility of the horse, whilst at the same time he lowers the hands and slackens the grip of the fingers, if necessary, to allow of the movement.

The hands, nevertheless, ought to be ready to resist, and even to act, if necessary, in order to regulate the pace, when the effect produeed by the legs is greater than was intended.

To lengthen the stride, the rider, without ever losing contact with the mouth, gives the greatest liberty to the horse, so as to allow the extension of the neck. In this position the horse is most firm on his legs, has a better view of the ground, and finds himself in the most favourable position for moving his legs without fatigue. 


\section{EMPLOYMENT OF' TIIF, TRAINED HORSE 131}

To lengthen the trot one should press the horse forward and keep him from taking an oblique position, by preventing cither of the shoulders preeeding the other. 'The rider will get assistance from rolding the reins separated in the two hands, so as to be able to use with greater ease the opposing actions of the reins.

The horse which, when pressed in the trot, takes the gallop without being asked to do so, is nearly always a lazy horse; he should be corrected when he makes this fault, pressed forward, allowed to stretch out his neck, and be brought to take a hold on the bit which favours the specd.

On the other hand, to reduce the speed of the gallop, the trot, and the walk, to change from the gallop to the trot, from the trot to the walk, from the walk to the stop, and to make the horse rein back, the rider fixes his hands and straightens his body, the fingers being lightly closed on reins of a right length. The legs should be ready to resist and eren to aet, if necessary, that is to say if the effect produced by the reins is greater than the rider desired. They have not, consequently, oceasion to intervene, till the horse has commenced to yield to the action of the reins.

To maintain a certain pace and speed.-In the ease of well-balaneed horses, which, whilst moving forward, are obedient to the aids and respect the rider's hand, it is sufficient, in order to keep them in a pace and speed desired, to maintain a gentle tension on the reins.

To keep the horse light in hand and to force him to yield the lower jaw to the bit, the pressure of the fingers on the reins should be intermittent, whilst the impulsion is still maintained. 
But it often happens that either because he pulls, or, on the contrary, because he lacks impulsion, the horse does not preserve the regularity of the paces.

'The horse pulls for many reasons: nervousness, want of balance, contraction, etc. These various causes are felt by the hand in two ways-

Either the rider feels on his hand the weight of a dull mass, heavy to carry, and difficult to displace (horse on his shoulders), in which case it is called resistance of weight, and is met by the half-halt, which obliges the horse to pull himself together and carry himself. Or the rider feels in his fingers a resistance arising from museular contractions of the lower jaw, and that the horse resists instinetively or voluntarily the action of the bit: we call these defences wilful resistances, and we attack them with flexions or vibrations on the reins as previously explained. The horses can, moreover, move slower than desired owing to laziness, want of energy, fear of the hand, or from ignorance of the position favourable to the movement.

If it is owing to laziness, we should attack strongly with the legs and, if necessary, press in the spurs, in order to re-establish the absolute respect for the leg.

If it is owing to want of energy, training, age, and good food, gradually increase the vigour of the horse. If the horse fears the bit, he shows his apprehension by raising his head and refusing the hand; he thus orerwhelms his hindquarters, and instead of collecting himself, trots without moving forward. We should in this case put a lighter bit in the horse's mouth, put him in confidence on the hand by gentle movements of the fingers, and provoke the extension of the neck, which will bring about the relaxation of the loins, and later on the propulsive action of the hindquarter's. 
To sum up, in the ease of a trained horse, keep the pace equal by means of a light hand and mobile fingers, without ever allowing the horse to pull.

In the ease of a horse which fights against the bit, one should have a light hand with always the same steady tension on the reins, or make use of ribrations. In the ease of a horse heary in front, one should close the fingers strongly on the reins and make use of the half-halt.

In each of these eases the legs should be fixed but passive.

Finally, in the ease of horses who are behind the bridle, seck the eause of the want of impulsion, and have recourse either to the action of the aids, or to some modification in the general treatment or in the work.

Change of direction.-The turn is mercly the consequence of a new objective that the rider proposes to reach. The selection of direction should, therefore, always preeede the turn.

In practice there are three ways of turning-

Turning on a large bend.

Turning on a small bend.

Turning from a stationary position.

1. The turning on a large bend is earried out whilst moving forward, and on an are of a circle sufficiently great, consequently the rider has scope and time. It is obtained either with the opened rein or with the indirect rein.

The opened rein indicates to the horse the new direction: the two legs press him in this direction : it is the most elementary of the turns whilst advancing. It is also the one which young horses best understand, and should, therefore, not only be used at the 
commencement of the breaking, but also every time that the horse resists the other effects of the reins.

In order that this turning may have its full effect it is of the greatest importance not to annul, by a premature intervention of the regulating rein, the action of the rein which determines the turn; one should, therefore, at the start, yield freely the opposite rein.

The turn with the indirect rein and the two legs is also a turn whilst going forward. The weight of the neck inclines the horse to the new direction, towards which the two legs press him: it is the turn most usually employed when riding in the open. It is also the only one which the rider who holds his reins in one hand is able to make use of. As in the preeeding turn, it is neeessary, in order that the rein which determines the movement may have its full effect and power, that the regulating rein be slack at first, so as not to interfere with the position which the horse's nose should take under the influenee of the direct rein. When riding with one hand, the slackening of the outside rein, morcover, takes effect automatically.

2. The short turn, which the rider makes use of when he is foreed to change his direction quickly, or when he has not much spare room, ean be obtained cither by a lateral or diagonal effect. The lateral effect (right direct rein of opposition and right leg) draws the shoulders to the right, and turns the quarters more or less sharply to the left: the horse turns his head to the right whilst at the same time slackening his speed. This turning is of general use during the training, it gives a short but energetic exereise to the spinal column, to the shoulders, and to the quarters. It is equally this movement which enables the rider to 
give his horse the first lesson in the use of the leg, and makes him aceept this aid. The short turn by the diagonal effect (left indirect rein of opposition and right leg for turning to the right) is the closest, the most prompt and the most correct of the turns. The left rein pushes the shoulders to the right, and the horse turns his head to the right without slackening his specd. To sum up, of the two large turns, the first is the most clementary; the sceond the most usual, in open air horsemanship: of the two elose turns, the first is excellent to enforce obedienee to the legr ; the second is the more rapid and regular.

3. The turn from a stationary position is employed when the rider, being at a stand, wishes to change direction : it is made on the shoulders, on the quarters, or on the centre. The half-turn on the forehand, when exceuted correctly and rapidly, proves the submission of the horse to the leg, and the suppleness of the hindquarters. The half-turn on the quarters, executed correctly and rapidly, proves the lightness of the forehand, the suppleness of the shoulders, the strength of the loins, and the submission of the hindquarters. If one carries out step by step these two movements, the horse will better understand the mechanism, but they have not the same suppling effect; one should, however, exceute them very slowly if wishful to get the best results.

The half-turn on the shoulders, and the half-turn on the quarters, are difficult to exceute perfectly. The half-turn in place, in which the horse pirots on his centre by carrying, for example, his shoulders to the right and his quarters to the left, is of casy execution and constant application. It is obtained by the action of the left rein indirect of opposition, which carries the 
shoulders to the right and mores the quarters to the left, and by the action of the right leg, which equally pushes the quarters to the left. In all the changes of direction the action of the leg should precede the action of the hand. By acting otherwise the quarters prop and make the turning clumsy. By, on the contrary, inclining the seat of impulsion in the new direction, the hindquarters act as a rudder, and impose the direction which the hand has only to indicate.

The Gallop. Galloping a horse.-The want of breeding in the troop horse, makes it necessary to be very careful in the use of the fast paces, and puts a limit on the degree of speed that one can exact from them, and also on the distance for which they can be exercised.

Nevertheless, the practice of the charge, makes it necessary for the soldier not only to make use of the extended gallop but also intermediate speeds. The instructor carefully regulates the details of this work, chooses his day, and ground, and gradually teaches his men and horses to take and maintain a steady gallop.

In these exercises the rider takes care to press the horse into the bridle. The greater confidence the horse has in the support of the hand, the better he places himself to ensure speed. There is also an advantage, at first, in riding him in a snaffle or double snaffle. The first gallops are made easier by the horses being arranged in groups of two or three at most, according to their temperaments. In the gallop, the rider should have his stirrups "home," the thighs closed in, and the legs fixed to the horse's sides, he should also lean slightly forward, so as to ease the horse's loins of weight, allow the hindquarters 
to act with more power, and consequently to ensure the greatest speed

The reins should be separated, the hands low resting on the neck, so as to be fixed, and to give the horse a firmer and more constant support.

The rider is taught to gradually increase the speed, up to the fastest gallop, and then to gradually slow down the pace, wnilst always maintaining contact with the horse's mouth and keeping him straight. These exereises comprise increasing and decreasing the speed; the gallop should not exeecd 800 yards. It is necessary to be careful and to regulate the work, according to the age and breed of the horses. The periods of walking which follow should be all the more prolonged, according as the gallop has been long and fast.

One makes use of this work to teach the rider to judge the speed of his horse, to regulate it, to see and make a note of, and reason about all that passes around him: in a word, to acquire a head, that is to say, the qualities of coolness, and quick observation and judgment, which are indispensable in war, and which the soldier should retain eren at the fastest paces.

Riding across country and over jumps.-The main principles of horsemanship find their application when riding orer a country and when jumping. The qualities of dash, of scat, of fixity, of suppleness, the care of the horse's mouth, the observance of the laws of balance, which hare been constantly mentioned in the education of both man and horse, here play a considerable part. Decision when jumping is one of the first qualities that an outdoor rider should possess: it communicates itself rapidly to 
the horse, and becomes the best guarantee of his boldness. If the rider is not keen, the horse soon finds it out and becomes restive. The seat, which is the close and supple contact of the pelvis and thighs with the horse, insures the lightness of the hand, gives the rider the use of his legs, which become more than ever the agents of impulsion, and enable him in case of mishap to save a fall by sinking into the bottom of his saddle.

The seat is independent of the body: a rider can have the body slightly inclined forward and still be close to his saddle, in the same way as he can have his body back and yet be out of the plate.

Fixity, which has been defined in horsemanship as the absence of all involuntary and useless movement, forbids here all exaggerated projection of the body, all displacement of the legs forwards or backwards, as also all movement of the hands.

Suppleness is the result of a good seat and fixity united by the suppleness of the loins; it is the essential quality which enables the rider to be one with his horse in all the variations of pace; it is what is ealled going with one's horse.

The laws of balanee and the mechanism of the paces demand from the rider that he should not overcharge the working parts when jumping, that is to say, the hindquarters, the seat of impulsion, at the moment of the spring, and the forchand, which supports the weight when the horse lands.

Finally, the play of the neek, all the more pronounced in proportion as the pace is slow and the spring violent, demands that the rider's hand gives the head a liberty proportioned to the cnergy of the extension, so that the horse may be able to 


\section{EMPLOYMENT OF TIE TRAINED HORSE 139}

utilize all his power, and that his mouth may not suffer from any involuntary movement.

No matter what the pace may be, when approaching the obstacle, the rider should fix his legs and increase their pressure, if necessary, to secure impulsion. He should incline the body slightly forward, the seat bones being still pressed into the saddle; the hands, placed low, accompany the movement of the neck, whilst the fingers release their hold on the reins to allow the horse the free use of his head and neck.

In thus riding his horse with impulsion, held firmly between fixed legs and long stretehed reins, the horseman gires his horse liberty between the aids, and places him in the best position for jumping. In fact, the formula which best sums up the instruction to be given to the riders when jumping, is, not to jump before the horse, nor after the horse, but with the horse. 


\section{CIIAPTER II}

RESISTANCES OF THE RIDING HORSE

The resistances of the horse are very rarely caused by wickedness or a bad disposition. They arise sometimes from a defective conformation, or from defects, visible or invisible, which make obedience painful, and force him to try and free himself from the effort required.

But it is most often the ease that the ignorance or awkwardness of the rider are responsible for the bad habits and resistances of the horse.

The horse, as has already been shewn when studying his mental constitution, is for erer taking his rider's measure, and he is a past master at finding out the form of resistance which the latter is most afraid of ; rearing, resistance on slippery parements, or beside a wall, ete. If the animal discovers the timidity of his rider, or feels the powerlessness of his aids, he immediately feels his own power, abuses it, and gets the upper hand.

On the other hand, restiveness rarely occurs when a horse (even one with a bad character) is entrusted to an energetic intelligent horseman with method, and determination to overcome difficulties. The vigorous application of certain rules of horscmanship and of 
breaking, laid down in the preceding pages, will nearly always bring suecess.

'To the brutal and superior forec of the horse, the rider should oppose skill and tact; he will take carchul note of the nature of the resistances, their cause and their seat (mouth, shoulders, quarters or pain).

IIc will divide the difficulties, and as much as possible, attack them separately (stop, relax, place, attack).

He will remember that the scat and fixity give the aids their greatest power with the least effort; when a fight is necessary he will preserve his eoolness; he will not squander his strength, but, on the contrary, coneentrate it on the right spot at the right time.

Alongside these first principles-knowledge, the control and economy of strength-there exists for the domination of a difficult animal, a number of methods, natural or artificial, which study and experience have disclosed, and it is for the rider to employ them aecording to his temperament and that of the horse, and to apply them in the difficulties, special or unforeseen, which arise during the training, or in the daily work of the horse.

Ignorant horses.-When a horse disobeys out of ignoranee of what is required of him, by merely showing anxiety or a passive resistance, one should recall him to obedience by taking up his training from the point at which he is at fault, and then following the series of exerrises laid down for the completion of his education.

Nervous and frightened horses.-It is by kindness and patience that one sueceeds in giving the horse confidence. When his rider sees an object likely to frighten him, he should sink into the saddle, leave the reins long, pat the horse and ealm him with the roice. 
If the horse has constantly fear of the same object, it is preferable to get off and familiarize him with the object, rather than force him up to it with the spurs. If the horse tries to turn round the rider should keep him on his right road by opposing the shoulders to the quarters.

Badly shaped horses. - The badly made horse naturally suffers the consequences of having inherited weak organs, and refuses to execute movements which throw special strain on these organs. The rider should avoid immoderate demands, which will but provoke resistance if the horse is weak, or ruin still further the defective parts if he tries to carry them out.

Restive horses. - To master a horse with a difficult character, the rider should prove himself the stronger, and never let pass an act of disobediencè or yicld to a whim. It is, however, rare that one can get him to yield without using foree; on the other hand, overy concession on the part of the horse should be immediately recompensed. With the horse who no longer obeys the pressure of both legs, the instructor is obliged to return to the lesson of the legs given with the lunge and the long whip.

Horses which rear.-To put up this defence a horse must first stop or hang back. The first thing to do is, therefore, to prevent this hanging back, by pressing the horse forward and bringing the weight on to the forehand.

If the horse refuses to go forward, one should turn him round, so as to relax the muscles which arc necessary for the rear. By mobilizing the hindquarters, by moving them to one side, one relaxes all parts of the horse, and prevents him from placing his weight on to his hindquarters. 
'The employment of the rearing bit helps in overcoming this defence. The reins of the bit passed over the neck and between the forelegs, and fastened at a suitable length to the girths, make the best and simplest rearing bit.

Horses which kick. - If a horse has the habit of kicking, one should make use of the bridoon to prevent him from lowering the head, and at the same time, press him strongly forward with the legss.

It is a mistake to always hold a kicker's head very high, for it often happens that the kicking is caused by pain in the loins or hocks, and by raising the head of certain horses one only increases their irritation and provokes their resistanee.

The horse which kicks at the boot, should be taken back to the lesson of the single leg with the lungingrein and the long whip. Every time that he defends himself in this way the rider should immediately reply by applying a vigorous stroke of the spur.

Horses which fight against the hand.-The causes of this fault are many. They arise generally from an excessive sensibility of the bars of the mouth, from a badly chosen bit, or from too severe a hand. One should find a suitable bit, and if necessary take off the curb chain.

The martingale attached to the noseband can be advantageously used in this case, as also work on the lunging rein, the horse being properly reined on to a dumb jockey.

Horses which overbend.-The horse overbends from weakness or want of training. This is the case with many young horses. It is sufficient to give them confidenec in the hand, by forward movement with an extended neck. If this attitude becomes a defenec, 
onc can use the bridoon reins to raise the head, with, if necessary, a short but vigorous action from below upwards. The desired result having been obtained, the legs should prevent the horse from moving slower. One should not at first be exacting, and should yield when the horse raises his head slightly in relaxing the lower jaw.

The gag snaflle also helps in orcrcoming this defenee.

Horses which poke their noses.-The horse which pokes his nose, holds his head high, and more or less horizontal, the jaw being contraeted; a bad eonformation predisposes to this fault, but this defective position generally comes from the horse being badly ridden, and consequently in fear of the hand. To correct it one should fix the hand just above the pommel of the saddle, the roins remaining stretched, close in the legs, press the horse into his bridle, and close the fingers strongly on the reins until the horse lowers the head slightly; one should then immediately relax the fingers and yield. Repeat this lesson until the horse yields to the least pressure of the fingers, and learns that the hand is only hard when he pokes his nose, and that it yields the moment he places his head properly. The use of the rearing bit, and also the fixed or running martingale, suggest themselvés in this defence.

Excitable horses. Horses which niggle.-The reasons which cause excitement and make a horse niggle are many. Some horses have too short a step in the walk, and training should put this right. Others lack impulsion and shrink from the leg: one should renew the lesson of the spur, and keep them moving forward. Others, owing to exeessive nervousness fidget, move sideways, and camnot support the pressure 
of the ranks. 'They should be made to work for some time by themselves, and be put into good condition, as fat makes the nerves less sensitive; the rider being told to sit as still as possible.

But in most cases the fault arises from the horsc, owing to fear of the hand, not daring to take from the bit the support which assists the free extended paces. The instructor should, in this case, change the rider whose aids are too severe, and make the horse extend his neck several times, in order to give him confidence in the hand, and to carry his weight on to his shoulders. These first results obtained, one relaxes him by long, slow trots, on bending courses, circles, and figures of eight in order to gradually get him used to the aids.

Horses which pull.-Being at the walk, stop him with an upward action on one rein; when he yields, let him straighten himself, and restart the walk. Repeat this lesson first at the slow trot and then at the ordinary trot. In this way one succeeds in overeoming the stiffness of the horse that pulls, by forcing him to bend himself, and engage his hind legs.

Work at the slow trot, on volts, serpentines, and diagonal lines, stops and half-stops, constitute an excellent exercise for a horse which is on his shoulders and leans on the hand.

Horses which open their mouths or pass their tongues over the bit.-For the first, make use of a noseband, or of a strap, tied either above or below the corner of the mouth. In the case of those which get their tongues over the bit, use a noseband and a bit with a pallet made of leather or indiarubber, or tie the tongue down with a strap. 


\section{APPENDIX}

Example of a "reprise" which might serve as a preparation of an officer's charger for the championship.

This "reprise" designedly composed of numerous movements, gives the horseman the opportunity of attempting all the difficulties of horsemanship, and a jury the means of assuring themselves-

1. That the horse moves straight at the various paces.

2. That he passes easily-as well on the straight line as in the changes of direction-from the slow cadenced paces to the extended paces.

3. Of appreciating the degree of obedience of the horse by the facility, more or less great, with which he moves - to both hands-his quarters round his shoulders, and his shoulders round his quarters.

4. Of judging the power and delicacy of the rider's aids, the movements demanded being carried out between lines and points carefully fixed.

The judges, in order to be able to form an exact opinion as to the precision with which the work is done, should stand in the centre of one end of the riding school.

The walk.-Towalk the length of the school and back.

Whilst eoming down the centre of the school, with the right leg elosed into the horse, and the hor'se's near quarter inclined slightly to the left.

After a few side paces, complete the hall-turn on the shoulders. 
Whilst going up the school, with the left leg closed in and the horse's off-quarter inclined slightly to the right.

After a few side paces, complete the half-turn on the shoulders.

Come down the middle of the school, and on arriving in front of the judges, collect the horse on to his quarters, and make a half-turn to the left.

Return up the centre of the school, collect the horse, and make a half-turn to the right.

The trot.-At the free strong trot, with the wall on the right, make a large turn to the left. Cross the school, change direction, and make a large turn to the right.

At the eadenced trot, the wall on the left, half-turn to the ecntre, and then return to the track with the horse placed diagonally, moving on two lines.

The wall on the right, half-volt on the forehand, proceed to the eentre of the school, the horse moving sideways.

The wall on the left, move diagonally across the sehool, and change to the other hand by moving the quarters round the shoulders.

Cross the school again diagonally, and then change the hand again by moving the shoulders round the quarters.

Wall to the right: trot fast half round the school, and then decrease the pace.

At the eadeneed trot move sideways across the school, and then come back to the same hand by moving the quarters round the shoulders.

Cross the school again diagonally, and come back to the same hand by moving the shoulders round the quarters. 
At the English trot on a serpentine course, increase the speed, decrease the speed, increase it again, halt, go backwards, trot again.

Trot up the school. On leaving the centre line turn round to the right on the quarters, then turn round to the left on the quarters, turn round to the left on the forehand, turn round to the right on the forehand. Walk down the centre of the school.

The canter.-Start the canter leading with the near fore leg, trot, then start into the canter, leading with the off fore leg.

Wall on the left, turn round to the right going as far as the centre of the school, then turn round in half the distance from the wall.

With the wall on the right turn round to the left, going as far as the centre of the school, then turn going only half this distance. Canter down the centre, turn sharply on the off hind leg, change the leading leg, and turn on the near hind leg.

Return down the centre of the school, make a half sharp turn to the left, change the leading leg. A close half-turn to the right, and change the leading leg.

Wall on right. Serpentine without changing the leading leg. Canter up the centre, half-turn on the forehand to the left, change the leg, half-turn on the shoulders to the left, change the leading leg, half-turn on the shoulders to the right and change the leading leg.

Wall on left. Serpentine along the eentre changing the leading leg at each bend. Change of leading leg at various intervals. 



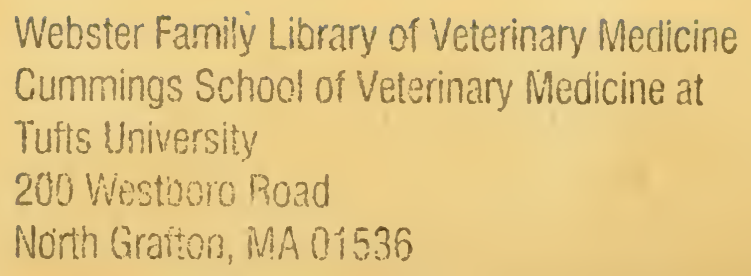



